\title{
CONSUMO (IN) SOSTENIBLE: NUEVOS DESAFÍOS FRENTE A LA OBSOLESCENCIA PROGRAMADA COMO COMPROMISO CON EL AMBIENTE Y LA SUSTENTABILIDAD
}

\author{
Consumption (In) Sustainable: New Challenges Facing \\ The Scheduled Obsolescence as Commitment \\ To the Environment and Sustainability
}

\author{
ADRIANA NORMA MARTÍNEZ1 ${ }^{1}$, ADRIANA MARGARITA PORCELLI ${ }^{2}$ \\ ${ }^{1}$ Profesora Adjunta Regular de la Facultad de Derecho UBA. Jefa de la \\ División Derecho, Profesora Asociada Ordinaria, Universidad Nacional de Luján. \\ 2Profesora Adjunta Ordinaria, Universidad Nacional de Luján.
}

E-mail: info@anmart.com.ar

adporcelli@yahoo.com.ar

Recibido: 4 de Noviembre de 2016

Aceptado: 29 de Noviembre de 2016

\begin{abstract}
Resumen
El presente artículo reconoce como antecedente y forma parte de una investigación que aborda el análisis de los impactos de la Informática en el ambiente, las diferentes propuestas legislativas y tendencias en tecnologías verdes - Green Computing, Green IT- en el ámbito nacional e internacional. En la misma, partimos de la base del reconocimiento que los grandes avances tecnológicos producidos en las últimas décadas derivados de las revoluciones industriales, específicamente de la tercera revolución industrial, han generado importantes consecuencias y profundos cambios sociales en el ámbito de la información y las comunicaciones, incidiendo en nuestras vidas y que, en la actualidad, el crecimiento económico, el desarrollo industrial, la generalización en el uso de las computadoras, la proliferación de redes informáticas y las modernas tecnologías de la información y comunicación (denominadas TICS) han aportado un nuevo grado de confort y bienestar a nuestra vida ocasionando un aumento del consumo de bienes y servicios. A partir de la década de 1930, los países adoptaron un modelo basado en la promoción del crecimiento del consumo lo que significó la reactivación de la economía gracias al incremento de la demanda, generando una sociedad consumista donde el tener y comprar determinó una posición dentro de la misma. Este artículo tiene por objeto describir la obsolescencia programada como una práctica empresarial habitual en la sociedad del consumo, sus diferentes modalidades, analizar los impactos negativos en las diferentes dimensiones del desarrollo sostenible para finalizar con la exposición de las alternativas propuestas tanto desde el ámbito del derecho como desde el económico-social. Palabras claves: Sociedad de Consumo, Ambiente, Tecnología, Obsolescencia Programada, Consumo Sustentable.

Abstract

The present article recognizes as precedent and forms a part of an investigation in which the impacts of the Computer science are studied in the environment, the different legislative offers and trends in green technologies - Green Computing, Green IT - in the national and international area. In the same one, we depart from the base that the big technological advances produced in the last decades, derived from the industrial revolutions, specifically from the third industrial revolution, generated important consequences and deep social changes in the area of the information and the communications, affecting in our lives. So it is so, at present, the economic growth, the industrial development, the generalization in the use of the computers, the proliferation of IT networks and the modern technologies of the information and communication (named TICS) have contributed a new degree of comfort and well-being to our life causing an increase of the consumption of goods and services. Since the decade of 1930 , the countries adopted a model based on the promotion of the growth of the consumption what meant the reactivation of the economy thanks to the increase of the demand, generating a consumer company where to have and to buy determined a position inside the same one. This article aims to describe the scheduled obsolescence as a normal business practice in the consumer society, its different modalities, analyze the negative impacts in the different dimensions of sustainable development to finish with the exposure of the alternative proposals from both the scope of the right as from the economic-social.
\end{abstract}

Keywords: Consumer Society, Environmental, Technology, Scheduled Obsolescence, Sustainable Consumption. 


\section{INTRODUCCIÓN}

\section{La sociedad de consumo}

En su discurso del 15 marzo de 1962 al Congreso de los Estados Unidos, el entonces Presidente John F. Kennedy efectuó afirmaciones que hoy permanecen vigentes. En el discurso titulado "Special message to Congress on protecting consumer interest, 15 March 1962", en su primera parte, el mandatario textualmente aseveró:

"Consumidores, por definición, nos incluye a todos. Son el grupo económico más grande en el mercado, que afecta $y$ es afectado por casi todas las decisiones económicas públicas y privadas. Dos tercios del gasto total de la economía provienen de los consumidores. Pero son el único grupo importante en la economía que no están eficazmente organizado, y cuyos puntos de vista, a menudo, no son escuchados."

En las últimas décadas, el crecimiento económico, el desarrollo industrial y las modernas tecnologías han aportado un nuevo grado de confort y bienestar a nuestra vida ocasionando un aumento del consumo de bienes y servicios.

Las medidas tomadas por los gobiernos, impulsadas fuertemente a partir de la década de 1930, llevaron a los países a promover el crecimiento del consumo lo que significó la reactivación de la economía gracias al incremento de la demanda, aumento de la oferta, del desarrollo industrial y la creación de empleo.

Sin embargo, este modelo trajo consigo consecuencias en las personas y en sus estilos de vida, generando una sociedad consumista donde el tener y comprar determinó una posición dentro de la sociedad.

A su vez, la sociedad de consumo solo es posible en una economía que produce bienes y servicios masivamente. Las políticas de crecimiento fomentan la demanda de productos y los consumidores son el motor de la economía. Se entiende que la economía de un país crece cuando su consumo y producción aumentan, pues ambos aspectos son interdependientes.

El consumo de productos y servicios es un hecho normal, es una actividad presente en todas las sociedades y en todas las épocas, pero recién en el siglo $X X$ es cuando se reconoce que el ser humano vive en una sociedad de consumo.

Para el reconocido sociólogo polaco Bauman (2007), el ser humano siempre ha consumido, pero recientemente esa actividad se convirtió en el eje de su vida y su razón de ser. En la actualidad ya no consumimos solo para sobrevivir sino para identificarnos y ser aceptados por un grupo social, para suplir carencias emocionales o para tener cierto estatus ante los demás. Una moderna sociedad de productores sentaba sus bases en una seguridad a largo plazo. En cambio, una sociedad de consumidores se distingue por un aumento permanente en la intensidad y volumen de los deseos, generando una producción de bienes con vencimiento fijo, una inestabilidad en los deseos y la insaciabilidad de las necesidades en un corto plazo. Lo más probable es que un objeto termine en la basura antes de haber dado alguna satisfacción a quien lo deseaba. En otras palabras, la vida acelerada que caracteriza al consumismo está basada en la necesidad de alcanzar las oportunidades que se presentan en el momento y que anuncian el peligro de desaparecer al instante, es decir, no consiste en adquirir y acumular sino en eliminar y reemplazar.

Tanto es así que la urgente necesidad de adquirir y poseer se debe complementar con la de eliminar y descartar, de lo contrario, se transformaría en un problema de almacenamiento a futuro. El citado sociólogo, recordando las palabras de Calvino, hace el paralelo de la conducta del consumismo con las costumbres de los habitantes de Leonia. $^{1}$

Las empresas, diluyendo las fronteras con el uso de las tecnologías de la información, se proponen dominar el mercado con la fabricación de símbolos culturales universales y con la homogeneización e internacionalización de los patrones de consumo y producción. Para Arias-Cáu \& Barocelli (2013), se busca unificar las necesidades creadas de la gente, estableciendo las mismas pautas y los mismos usos a nivel mundial, construyendo un paradigma donde los pertenecientes comen, se divierten, estudian, se visten, habitan, viajan, de una manera determinada, consultan o consumen determinados medios de comunicación.

El problema surge cuando ese consumo excede ciertos umbrales y se transforma en consumismo, que tiene como consecuencia la degradación ambiental llevando implícita la sobreexplotación de los recursos naturales y el difícil acceso a los bienes de consumo para los habitantes de países de economías desfavorecidas.

Con el paso del consumo al consumismo se produjo la revolución consumista, cuando el consumo -según palabras de Colin Campbell- se torna "particularmente importante para no decir central en la mayoría de la vida de las personas, el propósito mismo de su existencia"(Campbell 2005), vale decir

\footnotetext{
${ }^{1}$ Leonia era una de las ciudades invisibles de Ítalo Calvino, en donde no es tanto por la cantidad de cosas que son fabricadas, vendidas o compradas, que puede medirse la opulencia de Leonia sino más bien por las que son arrojadas para hacer espacio a las nuevas.
} 
que el querer, anhelar, desear y especialmente la capacidad de experimentar reiteradamente esas emociones es el fundamento de la economía.

La producción llegó a tal exceso que incluso se invirtió la lógica económica que prevalecía desde la Revolución Industrial hasta la primera mitad del siglo XX. Entonces se producían objetos para satisfacer necesidades. A la inversa, hoy se generan necesidades que solo se satisfacen con determinados objetos.

En una economía consumista, por lo general, primero aparecen los productos y sólo después se les busca alguna utilidad y si no consiguen despertar interés en los consumidores terminan en la basura. Este fenómeno de crecimiento exponencial de bienes y servicios se mantiene por el crecimiento de otro fenómeno: el exceso de información producida.

El consumismo es una relación especial con el consumo en la cual buscamos satisfacer nuestras necesidades emocionales y sociales haciendo compras, a la vez que definimos nuestra autoestima con base a las cosas que poseemos. Por otra parte, el hiperconsumismo es tomar más recursos de los que necesitamos y que el planeta pueda sostener.

Una de las características de la sociedad del consumo es la globalización. Aguilar-Benítez (2011) afirma, en términos generales que es un proceso económico, tecnológico, social y cultural a escala planetaria que consiste en la creciente comunicación e interdependencia entre los distintos países del mundo uniendo sus mercados, sociedades y culturas, a través de una serie de transformaciones sociales, económicas y políticas que les dan un carácter global. A menudo es identificada como un proceso dinámico provocado principalmente por las sociedades que viven bajo el capitalismo democrático o la democracia liberal y que han abierto sus puertas a la revolución informática. En lo técnico se relaciona con las nuevas tecnologías, con la elaboración y transferencia de información, uniendo regiones distantes; en lo ideológico-cultural puede entenderse como la universalización de determinados modelos de valor, por ejemplo, el reconocimiento de los derechos fundamentales, la democracia liberal y el modelo de consumo capitalista; y en lo económico con la liberación del tráfico de mercancías, servicios y capitales, la posición cada vez más dominante de las empresas multinacionales, el capitalismo como dominante y universal, no así la fuerza de trabajo. (Martínez \& Porcelli 2015).

A medida que el capitalismo se convirtió en el modelo económico dominante, la cultura del consumismo se volvió necesaria para sostenerlo. El profesor del Orbelin College, David Orr, define al consumidor de una manera lapidaria, a la vez que reflexiona de la siguiente manera:

\begin{abstract}
"Un "consumidor" es, entonces, "una persona que derrocha, destruye o consume". Desde este punto de vista más antiguo y claro, consumo implica trastorno, la enfermedad y la muerte. En nuestro tiempo, sin embargo, nos definimos orgullosamente no tanto como ciudadanos, o productores, o incluso como personas, sino como consumidores. Defendemos militantemente nuestros derechos como consumidores mientras nuestros derechos como ciudadanos se marchitan. El Consumo se transforma virtualmente en todo lo que hacemos. Hemos construido una economía, una sociedad y pronto un planeta entero sobre lo que alguna vez fue reconocido con una forma de enajenación mental. ¿Cómo pudo esto haber sucedido?" (Orr 2004)
\end{abstract}

En respuesta a su cuestionamiento, señaló que el surgimiento de la sociedad de consumo no fue inevitable ni accidental, sino que fue el resultado de la convergencia de cuatro fuerzas: la idea que la Tierra pertenece a toda la humanidad y que se puede tomar libremente todo de ella, el surgimiento del capitalismo moderno, la innovación tecnológica y la prodigalidad de América del Norte donde se sentaron las bases del consumo masivo. Dicho con otras palabras: la conducta del consumo fue el resultado de la seducción publicitaria, del rédito fácil, del desconocimiento sobre el contenido peligroso de la mayoría de productos que se consumen, la despreocupación por el futuro y la corrupción política.

En los inicios de la Revolución Industrial y hasta principios del siglo $\mathrm{XX}$, los fabricantes buscaban la durabilidad como cualidad inherente a sus artículos. Cuanto más resistente al paso del tiempo era un producto, mayor era la valoración obtenida por los consumidores, en consecuencia, mayor prestigio para la marca. Los consumidores empiezan a poner en valor otras cualidades de los productos, más basadas en el consumismo y en la moda que en las cualidades de duración, dejando a un lado valores como la resistencia al tiempo de los artículos.

Richard Sennett (2006), en sus análisis sobre la cultura del nuevo capitalismo, señaló que uno de sus rasgos más importantes es la idea de nada a largo plazo. El pasado está asociado a lo obsoleto y el futuro aparece como incierto y amenazante. En ese contexto, existe una fuerte tendencia a concentrar todo en el presente, en el aquí y ahora.

De acuerdo con la Organización de las Naciones Unidas (ONU), actualmente somos 7200 millones de habitantes, de 
los cuales 1.470 millones de personas (según el Foro Económico Mundial) se sumarán a los hábitos de consumo de la clase media en apenas dos décadas. La sociedad necesita un crecimiento económico sostenible, pero, en el futuro, no podemos darnos el lujo de ser tan ineficientes en la forma en que usamos los recursos y generamos desechos como lo hemos sido en el pasado. Precisamos crear nuevas tecnologías en la gestión de los recursos, así como nuevas formas de hacer negocios (WEF 2009).

Goñi (2015) comentó recientemente en el sitio web eldiario.es un estudio realizado por la Universidad de Berlín y el Öko-Institut en el cual se comprobó que los consumidores cambian heladeras, freezers, televisiones y computadoras más a menudo. Cada vez se renuevan con más frecuencia aparatos eléctricos o electrónicos que todavía funcionan. Se cambian por avances en la tecnología y por el deseo insaciable de los consumidores de disfrutar de esa tecnología de una porción cada vez más importante de grandes electrodomésticos como heladeras, lavarropas o secadoras, se reemplazan en los cinco años siguientes a su compra a causa de fallos técnicos. En la investigación se recogen estadísticas de diferentes tipos de electrodomésticos, bienes de equipo eléctricos e informáticos entre los años 2004 y 2012. Así, por ejemplo, en la renovación de los televisores con pantalla plana, un $60 \%$ se debe a la voluntad de los consumidores de comprar modelos más recientes. Sin embargo, no ocurre lo mismo con los grandes electrodomésticos, sólo uno de cada tres aparatos se cambia cuando todavía funciona y la mayoría son reemplazados debido a fallos técnicos. El estudio muestra que el porcentaje de electrodomésticos que se deben reemplazar en los cinco primeros años de su vida por esta causa se ha duplicado entre 2004 y 2012. Se ha pasado de un $3.5 \%$ en 2004 a un $8.3 \%$ en 2012. La misma tendencia se observa en las computadoras portátiles. Si la vida útil de estos aparatos se ha mantenido relativamente constante, alrededor de cinco o seis años, cada vez más se renuevan porque son defectuosos.

En 2004, un $70 \%$ de las computadoras fueron cambiadas porque los consumidores deseaban un aparato más moderno o por las innovaciones tecnológicas que estos presentaban. Sin embargo, ahora no ocurre lo mismo y sólo alrededor de un $25 \%$ de las renovaciones son debidas a esta causa. $^{2}$

Íntimamente relacionado con las nuevas tecnologías, podemos mencionar el fenómeno de las redes sociales que

${ }^{2}$ Estos datos se pueden revisar en OBSOLESCENCIA PROGRAMADA (editorial). La Opinión Edición digital del 30 de enero de 2016. (Fecha de acceso 10de marzo de 2016. URL disponible en:

http:/ / diariolaopinion.com.ar/noticia/83701/obsolescencia-programada comenzó cautivando a los adolescentes y actualmente se está extendiendo a todas las edades. Ya han dejado de ser una opción entre tantas otras para convertirse en el destino obligado de un creciente número de personas. Es evidente que los inventores y promotores de las redes virtuales han tenido una visión al estilo de Julio Verne. En el corazón de las redes sociales está el intercambio de información personal, han sabido captar una necesidad. Los usuarios están felices de poder revelar detalles íntimos de sus vidas privadas e intercambiar fotografías. Todo se expone en la red. Además, mayor parte de la vida social se encuentra mediatizada electrónicamente, vale decir, se desarrolla en compañía de una computadora, un iPod o un celular, y los jóvenes no poseen ni el más mínimo margen de maniobra o elección, sino que se trata de una cuestión de tómalo o déjalo, de lo contrario, sufrirían una suerte de muerte social.

Así es como el uso excesivo de los recursos naturales, el consumo acelerado e ilimitado, la gran cantidad de residuos y desechos de productos fabricados con materiales no degradables que son tratados en forma irresponsable, los modelos de producción insostenibles y la contaminación han llevado a la humanidad a una situación sin precedentes, que requiere medidas urgentes de fondo y de carácter global. Es la gran paradoja del actual modelo capitalista que permite a las empresas producir y vender productos diseñados para fallar en un plazo breve, solo para mantener al sistema artificialmente a flote, con una idea de falso crecimiento, mientras el ambiente y los consumidores son los grandes perjudicados. La sociedad consume más recursos que los que el planeta es capaz de reponer. Pero como no todos los habitantes-y por ende los paísesconsumen igual, las soluciones a esta problemática deben plantearse bajo el precepto de responsabilidades compartidas y diferenciadas, tal como se expresa en el principio siete de la Declaración de Río sobre el Medio Ambiente y el Desarrollo de 1992 y en artículo 4.1 de la Convención Marco de las Naciones Unidas sobre el Cambio Climático, 1992. Asimismo, en el Convenio Marco sobre Cambio Climático -Acuerdo de París 2015- las partes aplicaron los principios de la equidad y de las responsabilidades comunes pero diferenciadas teniendo en cuenta las capacidades respectivas, a la luz de las diferentes circunstancias nacionales. También reconocieron las necesidades específicas y las circunstancias especiales de los países en desarrollo, sobre todo de los que son particularmente vulnerables a los efectos adversos del cambio climático.

El actual modelo de producción y acumulación de riqueza económica se basa, en forma equivocada, en el supuesto de que los recursos naturales son infinitos. Conforme el Informe Planeta Vivo, 2015 de la Fundación Vida Silvestre 
(Word Wild Fund, WWF, por sus siglas en inglés), titulado Plataforma para la Agenda Pública Argentina 2016-2020, hay un déficit planetario del $40 \%$, que se estima alcanzará el $100 \%$ para mediados de 2030. Los actuales patrones de consumo mundiales son insostenibles. Los niveles de consumo globales son impulsados por el rápido crecimiento de la población mundial que se triplicó en los últimos 100 años y se espera que aumente un $30 \%$ más en los próximos 35 , llevando a la población a nueve mil millones para el año 2050. El aumento de la riqueza mundial y el consumo asociado a la inclusión de millones de personas de las clases pobres a las clases medias (tendencia que se espera que se triplique para el año 2030) y la aceleración de una cultura de "consumismo" entre los grupos de ingresos más altos, quienes representan la mayor proporción per cápita del consumo mundial. Por ello, la situación del ambiente global está íntimamente vinculada al consumo. Y en virtud de ello la solución requiere un cambio en las formas en que las personas consumen.

Tanto los líderes religiosos, como el Papa Francisco en la Encíclica Laudato Si, y la comunidad internacional a través de la Organización de las Naciones Unidas (ONU) en la Agenda 2030 para el Desarrollo Sostenible con los Objetivos de Desarrollo Sostenible y el Convenio Marco sobre Cambio Climático, 2015 -Acuerdo de París- alertan sobre las consecuencias del ritmo acelerado del consumo, de la cultura del descarte y de la alteración del ambiente. La propuesta apunta a que el progreso económico, social y tecnológico se produzca en armonía con la naturaleza, a proteger al planeta de la degradación, incluso mediante el consumo y la producción sostenibles, a sanar y proteger nuestro planeta y a tomar las medidas audaces $y$ transformativas que se necesitan urgentemente para reconducir al mundo por el camino de la sostenibilidad y la resiliencia (ONU 2015).

En el Capítulo Cuarto ("Una Ecología Integral") de la Encíclica Laudato Si, el Papa Francisco, en referencia al ambiente, señala la relación entre la naturaleza y la sociedad que la habita. Estamos incluidos en la naturaleza, somos parte de ella y estamos interpenetrados. Dada la magnitud de los cambios, es fundamental buscar soluciones integrales que consideren las interacciones de los sistemas naturales entre sí y con los sistemas sociales. No hay dos crisis separadas, una ambiental y otra social, sino una sola y compleja crisis socio-ambiental. De igual manera, conforme al principio cuatro de la Declaración de Río sobre el Medio Ambiente y el Desarrollo de 1992 la protección del medio ambiente no puede considerarse en forma aislada sino como parte integrante del proceso de desarrollo. Al respecto no puede hablarse de desarrollo sostenible sin una solidaridad intra e intergeneracional.
El Papa Francisco, en la Carta Encíclica Laudato Si afirma:

"La cultura ecológica no se puede reducir a una serie de
respuestas urgentes y parciales a los problemas que van
apareciendo en la degradación del ambiente, al
agotamiento de las reservas naturales y a la
contaminación. Debería ser una mirada distinta, un
pensamiento, una política, un programa educativo, un
estilo de vida. Buscar sólo un remedio técnico a cada
problema ambiental que surja es aislar cosas que en la
realidad están entrelazadas y esconder los verdaderos y
más profundos problemas del sistema mundial"
(Francisco 2015).

Es importante destacar que sin detener la creatividad humana y el progreso sino orientando esa energía con cauces nuevos, también podemos descubrir oportunidades diferentes. Como señalamos anteriormente, la cuestión ambiental atraviesa todas las disciplinas y categorías jurídicas y la Sociedad del Consumo y de la Información, respaldada en las Tecnologías de la Información y la Comunicación (TICs), además de una revolución tecnológica constituye un cambio en los modos de existir, de pensar y de relacionarnos con el mundo y con los demás.

La evolución de la creciente interdependencia de los Estados motiva que lo que suceda en un Estado no permanezca indiferente en los demás, las fronteras se diluyen, vivimos en un mundo cada vez más pequeño y se reduce el tiempo y el espacio, lo que ocasiona que estemos frente a un fenómeno intrínsecamente internacional.

\section{METODOLOGÍA}

Tanto en el presente artículo como en el proyecto de investigación en el cual se encuentra enmarcado, el abordaje está relacionado con la observación documental y el análisis del contenido en base a la triangulación de la información de las distintas fuentes proveniente de todas las áreas comprendidas.

La metodología se organiza a partir de los ámbitos de análisis: ambiental, social, económico, informático e internacional y consiste en:

a) Relevamiento, revisión y sistematización de la bibliografía existente sobre el tema.

b) Elaboración y clasificación de conceptos teóricotécnicos específicos. 
c) Relevamiento o recolección de información en fuentes secundarias.

d) Identificación, a partir del relevamiento, recopilación y sistematización metódica, la normativa internacional, regional y nacional vinculada al objeto del presente proyecto.

\section{MARCO CONCEPTUAL: OBSOLESCENCIA PROGRAMADA O PLANIFICADA}

Los artículos tienen un ciclo de vida natural, desde su fabricación hasta su caducidad, bien por agotamiento, bien por rotura irreparable. Sin embargo, la obsolescencia programada hace referencia a una caducidad deliberada, concebida desde su diseño por el fabricante para que las cosas no duren más allá del tiempo deseado por ellos mismos utilizando materiales menos consistentes, menos duraderos, baterías agotables o incluso, introduciendo chips con contadores que limiten el uso hasta un determinado número de veces. Al hablar de obsolescencia programada nos referimos a una práctica comercial consistente en la planificación del fin de la vida útil de un producto o servicio, de tal forma que, tras un cierto periodo de tiempo determinado (calculado por el fabricante o por la empresa) quede obsoleto o inservible $\mathrm{y}$, por lo tanto, debe ser sustituido.

Podemos afirmar que la expresión se refiere a la elaboración programada de productos de consumo que se volverán obsoletos en el corto plazo por una falla programada o bien una deficiencia incorporada por el productor. La finalidad perseguida por los productores es económica, ya que al elaborar productos con una vida útil limitada inducen intencionalmente a los clientes a seguir comprando nuevas versiones de estos productos a medida que falla o muere el anterior. Reparar el daño es más costoso que adquirir uno nuevo. Como las economías modernas se basan en el endeudamiento y el crédito, gran parte de los productos se planifican para durar mientras se siguen pagando, de tal forma que crean una dependencia entre producción, consumo y crédito, y así el sistema financiero justifica su existencia.

En el libro "La historia de las cosas", The story of stuff en inglés, Leonard (2010) describe, con una fuerte crítica, nuestros patrones de producción y consumo, afirmando que los productores advirtieron que había un límite para la cantidad de las cosas que las personas podían consumir y si las fábricas seguían produciendo, se provocaría una saturación total, un exceso de oferta, y ese exceso sería perjudicial para los negocios. En consecuencia, comenzaron una estrategia para que los consumidores siguieran adquiriendo bienes: "la obsolescencia planificada".

Tal concepto se remonta a 1932, cuando Bernard London, un agente inmobiliario, propuso terminar con la crisis de la Gran Depresión a través de la obsolescencia planificada. En su texto, London proponía la creación de un organismo gubernamental que se ocupara de asignar fechas de caducidad para productos de consumo específicos y que los consumidores los entregaran para su reemplazo aun cuando funcionaran correctamente. Ese sistema mantendría a las fábricas en actividad. Su objetivo era obligar a los fabricantes a producir objetos que rápidamente se deterioraran y que tuvieran que ser sustituidos por otros nuevos para así reactivar la industria y la demanda de productos. Aunque nunca se llegó a imponer por ley, muchas empresas lo tomaron como modelo de línea de negocio, especialmente en el rubro de la electricidad y las lamparitas de la luz. Sin embargo, alcanzó su mayor popularidad en 1954 cuando Brooks Stevens, diseñador industrial de Estados Unidos de América, dio una conferencia sobre lo que suponía la nueva producción en masa y lo que implicaba económicamente una producción más barata y con precios más bajos, utilizando de este modo el término de obsolescencia programada.

El documental de la Televisión Española "Comprar, tirar, comprar", del año 2011, dirigido por Cosina Dannoritzer nos ilustra sobre los principales efectos y consecuencias de la obsolescencia programada. Rodado en España, Francia, Alemania, Estados Unidos y Ghana, este documental, hace un recorrido por la historia de una práctica empresarial consistente en la reducción deliberada de la vida de un producto para incrementar su consumo porque, como ya publicaba en 1928 una revista de publicidad norteamericana, "un artículo que no se desgasta es una tragedia para los negocios".

En el mismo se enumeran varios ejemplos como el de las lamparitas de luz. El 21 de octubre de 1879, Thomas Alva Edison presentaba una lámpara práctica y viable que permanecía encendida durante 48 horas ininterrumpidas. Unos meses después, las autoridades estadounidenses le concedieron la patente del que se considerara uno de los inventos más útiles de la historia. Cuando Edison puso a la venta su primera bombita de luz, en 1881, su duración era de 1500 horas gracias a su filamento de gran estabilidad. Treinta años más tarde otros fabricantes anunciaban unas lamparitas cuya duración certificada era de 2500 horas. 
Han pasado casi dos siglos y cabría pensar que las bombitas de luz que utilizamos hoy en día son mejores que las de antaño. Pero no, son peores. Una lamparita incandescente convencional tiene aproximadamente unas 1000 horas de vida, lo que supone aproximadamente un año de uso. Es decir, casi 200 años después, con todos los avances que se han producido en el ámbito de la ciencia y la tecnología, no solo no utilizamos lamparitas mejores, sino que las actuales se estropean antes que las pioneras.

La razón se debe a que pronto los empresarios descubrieron que ir prolongando la duración de la vida de las bombitas de luz solo supondría el fin de sus lucrativos negocios. Por este motivo, el 25 de diciembre de 1924 se reunieron en Ginebra, donde decidieron crear un cartel mundial denominado "Phoebus", y pactaron que "la vida media de las bombillas de iluminación general no debía ser garantizada u ofrecida por otro valor que no sea las 1000 horas". Los productos de larga duración ya eran considerados como una desventaja económica para los empresarios, debido a que si los consumidores adquirían lamparitas que durasen muchas horas, tardarían mucho más en reemplazarlas.

Sin embargo, el cartel fue denunciado y, supuestamente, dejó de funcionar. No obstante, la práctica de reducir a propósito la vida de las bombitas sigue en vigor actualmente. A pesar de ello, una ha conseguido sobrevivir y lleva encendida 111 años en la estación de bomberos del condado de Livermoore (California). El libro Guiness de los records declaró a la misma como la bombilla de luz más antigua del mundo que seguía encendida con una potencia más bien escasa de unos 4W (RTVE 2011).

No obstante, una parte de la Biblioteca asevera que tales afirmaciones sobre la obsolescencia programada como un recurso general de la industria parecen algo exageradas. En los test de longevidad de bombitas se aprecia que su duración es inversamente proporcional a una potencia elevada -en el rango 12-16- del voltaje aplicado. Esto significa que para una disminución de la tensión de tan solo el $5 \%$, la duración de una lamparita aproximadamente se duplicaría. En base a esa relación, a la mitad de tensión nominal, la longevidad de la bombita aumentaría en un factor de al menos 4000 .

En realidad, afirman que muchos consumidores prefieren comprar más barato y con materiales menos resistentes, aunque dure menos tiempo. Algunos sectores de la industria tienen que competir fabricando productos con nuevas características demandadas por los usuarios, a precios cada vez más bajos en una especie de carrera frenética hacia el "made in china" generalizado. El mercado requiere que el productor, con el fin de mantenerse competitivo, disminuya sus costos en todas las fases del proceso de producción -costo-eficiencia-. Esto usualmente se traduce en el pago de salarios mínimos, tercerización, pero también en el uso de materiales de menor calidad y pobre diseño. A esto se le puede denominar obsolescencia intrínseca. Por lo cual, cuando se quieren imponer sanciones mediante legislación a la obsolescencia planificada, la estrategia adoptada por las empresas es enmascararla dentro de lo que se ha denominado obsolescencia intrínseca, suprimiendo o ignorando nuevas tecnologías que podrían suponer un producto más duradero, sostenible o amigable con el ambiente.

En la vereda de enfrente, el empresario español Benito Muros, propietario de la compañía OEP Electrics, considera que dicha práctica no es ética. "Los fabricantes que llevan a cabo estas prácticas -asegura-, no se dan cuenta de que están utilizando unas materias primas que cogemos del Tercer Mundo a muy bajo precio, para devolverlos después también al Tercer Mundo en forma de residuos muy peligrosos". Esto, a su juicio, "pone en peligro la sostenibilidad de un planeta ya mermado de recursos"3.(Muros 2014).

\section{Otros ejemplos de obsolescencia programada}

Además del clásico ejemplo de las lamparitas de luz, podemos mencionar los siguientes:

a) Cartuchos de tinta: en la mayoría de los casos, los nuevos cartuchos de inyección de tinta pueden costar más que la propia impresora, y vienen con chips inteligentes que desactivan la impresión cuando uno de los colores llega a un cierto nivel. La Organización de Consumidores y Usuarios (OCU), utilizando el método experimental arribó a la siguiente conclusión:

"Hemos analizado impresoras multifunción de inyección
de tinta, y la verdad es que en este análisis no detectamos
la práctica que denuncia el documental. Y eso que
algunas impresoras las analizamos usando 40 juegos de
cartuchos de tinta por modelo. ¿Podría haber pasado con
el 41 , io con otro modelo? Quién sabe. Pero resulta igual
de criticable que un solo juego de cartuchos pueda costar
casi tanto como la propia impresora (con un juego de
regalo), induciendo a cambiarla por otra nueva cada vez

${ }^{3}$ La visión de este empresario se puede consultar en 5.3 ALTERNATIVAS A LA OBSOLESCENCIA PROGRAMADA. (editorial) 2014. Revista Diseño Social. 6 de febrero de 2014. (Fecha de acceso 10 de octubre de 2016). URL disponible en: http:/ / disenosocial.org/obsolescencia-0512/. 
que se queda sin tinta. Porque el efecto es el mismo: la generación gratuita de residuos, con el consiguiente impacto ambiental, desde su producción hasta su reciclado"(OCU 2011).

b) Video juegos: en general, los juegos viejos no pueden ser jugados en las consolas nuevas. Cuando el Super Nintendo salió a principios de 1990, convirtió a la Nintendo Entertainment System en un aparato obsoleto. Esta falta de compatibilidad impulsa la venta de los nuevos dispositivos y de cada uno de sus juegos.

c) Software: al igual que el caso anterior, muchos programas son incompatibles con los archivos o las versiones anteriores. Actualizaciones que ofrecen mejoras y, sobre todo, una mayor seguridad. Sin embargo, una nueva versión de un sistema operativo, implica muchísimos cambios, ya que nos obliga a utilizar las actualizaciones más recientes de muchos de los programas que usamos en él. Pero el tema no termina en software, ya que los avances en los programas a menudo impulsan las ventas de hardware puesto que las versiones más nuevas requieren máquinas cada vez más potentes, con mayor memoria RAM, una pantalla táctil, mayor capacidad en el disco rígido y mucho más.

d) Los libros de texto: anteriormente, los libros de textos podían ser utilizados en años posteriores. Actualmente, en general, la información es la misma, pero se distribuye de manera distinta, se quitan y se agregan algunos detalles, por lo cual, los docentes piden la nueva edición y cierran el ciclo de obsolescencia de un libro que podría tener una larga vida útil.

e) Automóviles: el modelo $\mathrm{T}$ de Ford fue un éxito para la industria automovilística americana, pero estaba concebido para durar. En cambio, General Motors- su competencia-, dio retoques cosméticos a sus coches, lo que le permitió que los clientes cambiaran de modelo muy a menudo. Además, los fabricantes descontinúan partes que de otra manera podrían estar disponibles para las reparaciones. A diferencia de los primeros modelos, los automóviles son accesorios de moda, y, por tanto, sólo se los mantiene por unos pocos años.

f) Baterías y equipos electrónicos: muchos dispositivos como notebooks, reproductores de MP3 y tabletas, programan su obsolescencia a través de las baterías, es decir dura cada vez menos o alguna de sus partes se rompe al golpearse y no haya forma de cambiarla. Existen impresoras que dejan de funcionar al llegar a un número determinado de impresiones; lavadoras que se estropean a los 2500 lavados exactos y ya no se pueden reparar; televisores limitados en 20000 horas de duración. Uno de los casos más conocidos fue el de los primeros iPods, cuya batería estaba programa para durar entre ocho y doce meses. Apple recomendaba cambiar el aparato por uno más nuevo. Pocos meses después de salir el primer iPod al mercado, en medio de una tremenda campaña publicitaria, el director de cine estadounidense Casey Neistat y su hermano realizaron un vídeo en el que se denunciaba la corta vida de las baterías de estos aparatos. El problema consistía en que la batería estaba soldada al reproductor de música, con lo cual su inutilización obligaría al cliente a tener que cambiar el aparato por otro más nuevo al poco tiempo de haberlo adquirido por un elevado precio. El documental provocó una catarata de demandas por parte de los consumidores. El asunto se zanjó en los tribunales con el compromiso de Apple de asegurar dos años de vida en sus iPods y de crear un departamento de recambios para aquellos modelos que no ofrecían la posibilidad de un cambio de batería.

g) Como último ejemplo, según José Muñoz (2014), ingeniero de telecomunicaciones propietario de TPC Informática, todas las PCs mueren por calor, es decir, por temperatura. Para controlar la temperatura un portátil tiene un ventilador que gira sobre un plástico con muy poco coeficiente de fricción, que desliza muy bien. Sin embargo, si se está en un lugar con polvo, por ejemplo, la fricción comienza a ser mayor. Si la pieza se rompiera, sería fácil detectar el problema y repararlo, pero la cuestión es que empieza a tener más coeficiente de fricción, entonces el ventilador gira más despacio, disipa peor el calor o lo que es lo mismo, se calienta más el procesador. A partir de ahí, la notebook empieza funcionar más lento, se incorporan nuevas aplicaciones para que vaya más rápido, con lo cual se ralentiza aún más, por la carga de disco duro. Finalmente muere, pero claro, debido en su mayor parte al fallo en el buen funcionamiento del ventilador. La garantía, es en teoría de dos años; pero el fabricante, como considera que el ventilador es un componente mecánico, alega que la garantía sobre el mismo es de tan sólo un año. Para el ingeniero incorporar un rodamiento sería muy fácil y alargaría la vida de la computadora (Espinosa 2014).

\section{Clases de obsolescencia}

Vance Packard, economista y sociólogo, fue uno de los primeros autores en estudiar este fenómeno en su obra "The Waste Makers" es decir "Los Artífices del Derroche", y 
efectúa una tipología diferenciando las causas por las que se produce:

a) Obsolescencia de función: cuando un producto sustituye a otro por su funcionalidad superior.

b) Obsolescencia de calidad: el producto se vuelve obsoleto por un mal funcionamiento programado.

c) Obsolescencia de deseo: ocurre cuando el producto, aun siendo completamente funcional y no habiendo sustituto mejor, deja de ser deseado por cuestiones de moda o estilo, y se le asignan valores peyorativos que disminuyen su deseo de compra y animan a su sustitución.

Asimismo, podemos encontrar tres formas en que se manifiesta la obsolescencia programada:

a) Obsolescencia incorporada: podría fácilmente ser considerada como un delito, ya que provoca un perjuicio económico a los usuarios que adquieren el producto con expectativas de duración y disponibilidad.

b) Obsolescencia tecnológica: otra forma de obsolescencia es la actualización continua y rápida de productos como computadoras, de entretenimiento, telefonía móvil. Este concepto, conforme las palabras de Annie Leonard, difiere de la programada ya que el producto queda obsoleto por un real avance de la tecnología. Podemos hacer una lista de tecnología que desechamos debido a la velocidad del recambio tecnológico: casetes, videograbadoras, beepers, faxes, walkmans, CD, DVD, juegos electrónicos, como el Family, Sega, el Nintendo y la PlayStation. Sin embargo, las instancias en que la nueva tecnología en verdad supera a la vieja son en los menores casos, por ejemplo, los teléfonos celulares tienen una vida útil promedio de un año, casi nunca están tecnológicamente obsoletos cuando los tiramos y reemplazamos por nuevos. En ese caso estamos frente a la obsolescencia percibida.

c) Obsolescencia psicológica o percibida: en 1954, el diseñador industrial Clifford Brooks Stevens, citado por Annie Leonard, habló por primera vez de la obsolescencia percibida. La definió como "el deseo del consumidor de poseer una cosa un poco más nueva, un poco mejor y un poco antes de que sea necesario" (Leonard 2010).
Un gran número de electrodomésticos -especialmente los que se conocen como PAE (Pequeño Aparato Electrodoméstico)no duran tanto como en el pasado, y los fabricantes promueven nuevos productos en función de la moda y el lujo, haciendo que los modelos anteriores no sean atractivos. Con la ayuda de la maquinaria publicitaria se genera en el consumidor la necesidad de poseer el último modelo lanzado, antes de lo que realmente necesita. Se trata de manipular al consumidor para que se sienta valorado socialmente por contar con lo último en tecnología. El artículo no está roto ni obsoleto, sino que lo percibimos como obsoleto. Aunque podamos seguir utilizando el menos nuevo, hacen que nos encaprichemos con otro más grande y bonito, pero de similares funcionalidades.

La obsolescencia psicológica es común en la industria de la moda, pero actualmente las principales empresas de tecnología, imitando a la industria de la moda, sacan nuevos modelos con algún añadido que aparentemente los hace más novedoso. Las funcionalidades, en muchos casos, son las mismas o muy parecidas, lo único que realmente parece importante es la apariencia de "diferente y novedoso". ${ }^{4}$

En Argentina, el gobierno del presidente Macri lanzó, el 18 de julio de 2016, el Programa de Acceso a Internet MóvilPAIM-, por el cual se busca que ocho millones de argentinos cambien sus aparatos $2 \mathrm{G}$ y $3 \mathrm{G}$ por dispositivos $4 \mathrm{G}$, que podrán comprarse a \$2 200 pesos en doce cuotas sin interés. Los teléfonos que participan del programa tienen una pantalla de 4.3 pulgadas, procesador dual-core, cámara trasera y frontal, 512 megabytes de memoria (RAM) y unos cuatro giga de almacenamiento interno.

El estándar de 4G permite a los usuarios de dispositivos móviles contar con una mayor velocidad de navegación, tanto en la subida como en la bajada de datos ya que el $3 \mathrm{G}$ corre a un máximo de cinco megas mientras que con $4 \mathrm{G}$ se puede llegar a los diez o 20 megas. Más allá, la tecnología de $4 \mathrm{G}$ permite aliviar la saturada red $3 \mathrm{G}$ por lo que mejorará la navegación inclusive para aquellos que no tengan equipos de cuarta generación. El Gobierno estima que la demanda de estos teléfonos sumará al menos cuatro millones de aparatos por año. En la Argentina se comercializan anualmente entre doce millones y catorce millones de nuevos celulares (Crettaz 2016).

El programa registró en los primeros diez días de implementación una venta promedio de 20.000 nuevos

4Para mayor información consultar en OBSOLESCENCIA PROGRAMADA: TIPOS Y FORMAS (editorial) 2014. Eco inteligencia, 10 de junio de 2014. (Fecha de acceso 15 de octubre de 2016). URL disponible en: http://www.ecointeligencia.com/2014/06/obsolescencia-programada- 
celulares en cada uno de los tres principales operadores del sector. ${ }^{5}$ A modo de reflexión nos preguntamos el destino de los millones de celulares canjeados (sobre lo que nada se prevé en la iniciativa oficial, ni en otra complementaria) y si real y ambientalmente se justifica tal medida.

\section{DISCUSIÓN: IMPACTOS DE LA OBSOLESCENCIA PROGRAMADA EN LAS DIFERENTES DIMENSIONES DEL DESARROLLO SOSTENIBLE}

El concepto de desarrollo sostenible apunta a que la calidad de vida del ser humano, como bien jurídico tutelado, se alcance sin comprometer la capacidad de las generaciones futuras, entendiendo por tal a aquel tipo de desarrollo que satisface las necesidades de las generaciones presentes sin comprometer la capacidad de las generaciones futuras de satisfacer sus propias necesidades. Los líderes del mundo se reunieron en Nueva York para adoptar la Declaración del Milenio, aprobada por la Asamblea General de las Naciones Unidas en su Octava Reunión Plenaria (6-8 de septiembre de 2000). En ella los países asumieron el compromiso en una nueva alianza mundial para reducir la pobreza extrema y se establecieron una serie de ocho objetivos, con plazo límite de 2015, conocidos como los Objetivos de Desarrollo del Milenio (ODM), que proporcionaron un importante marco para el desarrollo, $y$ se han alcanzado progresos considerables en diversas esferas. Sin embargo, los avances han sido desiguales.

En la Cumbre Mundial para el Desarrollo Sostenible de Nueva York, 2015, los Estados Miembros de las Naciones Unidas aprobaron la Agenda 2030 para el Desarrollo Sostenible, que incluye un conjunto de 17 Objetivos de Desarrollo Sostenible (ODS) y 169 metas adoptadas, los cuales demuestran la magnitud de esta ambiciosa nueva Agenda universal, que guiarán las decisiones durante los próximos quince años. Se mantienen algunas prioridades de desarrollo, como la erradicación de la pobreza, la salud, la educación y la seguridad alimentaria y la nutrición, pero se establece además una amplia gama de objetivos económicos, sociales y ambientales.

Por otra parte, Tedesco (2010) plantea los desafíos que debe enfrentar la sociedad en red global en donde existen fuertes tendencias a la fragmentación social, derivados de la lógica de la desigualdad- inclusión-exclusión- con la cual opera el

\footnotetext{
${ }^{5}$ Estos datos se pueden consultar en MÁS DE 60.000 CELULARES VENDIDOS EN 10 DÍAS CON EL PLAN DE CUOTAS DEL GOBIERNO. (editorial). 2016. Diario La Nación. 1 de agosto de 2016. Sección Tecnología.(Fecha de acceso 1 de agosto de 2016) URL disponible en: http:/ / www.lanacion.com.ar/1923704-mas-de-60000-celulares-vendidosen-10-dias-con-el-plan-de-cuotas-del-gobierno.
}

nuevo capitalismo: concentración del ingreso, individualismo a-social o individualismo en red, consumismo diversificado. En síntesis, identifica tres grandes desafíos.

a) En primer lugar, un desafío político: representado por la crisis del Estado-Nación, todos los problemas de un orden económico y social más justo, reglas universales y formas de participación ciudadana que tengan alcance global.

b) En segundo lugar, un desafío tecnológico. El cambio climático, las fuentes no renovables de energía, la necesidad de garantizar niveles dignos de vida al conjunto de la población, requieren una revolución tecnológica orientada básicamente a incentivar la innovación tecnológica hacia la solución de los problemas sociales más significativos y no hacia la eliminación del trabajo humano y la rentabilidad de las empresas.

c) En tercer lugar, un desafío antropológico: los actuales patrones de comportamiento, de producción y consumo son incompatibles con la idea de un orden social justo y un planeta sostenible.

En este contexto y resaltando el marco actual de los acuerdos que fueron plasmados en diferentes instrumentos internacionales, partiendo de la Agenda 2030 para el Desarrollo Sostenible con los Objetivos de Desarrollo Sostenible y el Convenio Marco sobre Cambio Climático Acuerdo de París- y sin olvidarnos de la mirada coincidente aportada desde la Iglesia Católica en la Carta Encíclica Laudato Si del Papa Francisco, especificaremos los impactos negativos de la obsolescencia programada en las dimensiones ambiental, social y económico del desarrollo sostenible.

\section{Dimensión Ambiental}

Tanto el Papa Francisco (2015), en la Encíclica Laudato Si, como las Naciones Unidas en Agenda 2030 para el Desarrollo Sostenible con los Objetivos de Desarrollo Sostenible y el Convenio Marco sobre Cambio Climático, 2015 - Acuerdo de París-, alertan sobre las consecuencias del ritmo acelerado del consumo, de la cultura del descarte y de la alteración del ambiente. La propuesta apunta a que el progreso económico, social y tecnológico se produzca en armonía con la naturaleza, a proteger al planeta de la degradación, incluso mediante el consumo y la producción sostenibles, a sanar y proteger nuestro planeta y a tomar las medidas audaces y transformativas que se necesitan 
urgentemente para reconducir al mundo por el camino de la sostenibilidad y la resiliencia.

El Pontífice suma a ésta otra problemática referida a que todavía no se ha logrado adoptar un modelo circular de producción que asegure recursos para todos y para las generaciones futuras, y que supone limitar al máximo el uso de los recursos no renovables, moderar el consumo, maximizar la eficiencia del aprovechamiento, reutilizar y reciclar. Abordar esta cuestión sería un modo de contrarrestar la cultura del descarte, que termina afectando al planeta entero, pero observamos que los avances en este sentido son todavía muy escasos.

El actual modelo económico de consumo ha superado las posibilidades del planeta, al producirse cientos de millones de toneladas de residuos por año y, principalmente, impacta negativamente en el ambiente en dos grandes aspectos: la necesidad creciente de extraer recursos de la tierra que permitan fabricar mayor cantidad de aparatos, y por la generación cada vez mayor de residuos, que no se tratan y o reciclan adecuadamente. Esto es debido a la rapidez con la que un aparato tecnológico queda obsoleto, o es percibido por el consumidor como tal, y aparece la necesidad de reemplazarlo por otro, que aparentemente trae mayores prestaciones y que se creen necesarias.

\section{Extracción de recursos naturales no renovables}

En primer lugar, la extracción desmesurada de los recursos no renovables como los minerales genera el problema de su disponibilidad para las generaciones futuras. En segundo lugar, la minería como método extractivo primario ocasiona serios inconvenientes, sea subterránea o a cielo abierto. Se desalojan comunidades y se pone en riesgo la salud de los trabajadores y de la población en general. La minería subterránea implica cavado de túneles en las profundidades de la tierra, sin embargo, la minería a cielo abierto proporciona la mayor parte de los minerales extraídos. En esta última, primero se talan los árboles para despejar el área, se remueve la tierra y las rocas que cubren las menas con topadoras, explosivos y perforadoras, produciendo de ocho a diez veces más escombros que una mina subterránea. Pero la mina tiene una pequeña cantidad de metal puro por lo que es necesario procesarla utilizando gran cantidad de agua y sustancias químicas.

Entre los minerales utilizados en la elaboración de productos informáticos podemos mencionar:

Oro: el oro se emplea en la industria electrónica. Todos los aparatos electrónicos, como los teléfonos, los computadores portátiles, reproductores de MP3 contienen una pequeña cantidad de ese metal, aunque las mayores cantidades de ese mineral se destinan a la joyería. En la extracción de oro las empresas mineras apilan la mena aurífera y vierten cianuro por encima, como método de purificación, para que gotee lentamente a través de la pila, mediante el proceso denominado lixiviación. Pero el cianuro también extrae metales tóxicos como el cadmio, el plomo y el mercurio. El excedente de cianuro y de los metales tóxicos terminan en un estanque contaminado de cianuro y metales pesados. Además, el oro es el metal que más emisiones de dióxido de carbono genera al ambiente en su etapa de extracción primaria sumado al consumo de energía. Por ejemplo, para producir un gramo de oro se necesitarán: 380 litros de agua, dos litros de gasoil, $43.6 \mathrm{kwh}$ de electricidad, 1.1 kilogramos de explosivos y 850 gramos de cianuro de sodio (Greenpeace 2012).

Coltán: es una mezcla de dos minerales, columbita y tantalita, cuyas mayores reservas mundiales se ubican en la República Democrática del Congo, por eso se lo identifica como el responsable de la atroz guerra sufrida en dicho país. Se utiliza para fabricar radares militares, televisores de plasma, celulares, notebooks, GPS, playstations, y demás aparatos electrónicos. Entre otras propiedades, el Coltán permite que las baterías duren más tiempo, tiene alta resistencia a la corrosión y permite la miniaturización de aparatos, otorgándoles, además, mayor potencia. (Burgos 2016).

Plomo: es utilizado en la construcción de monitores y es perjudicial para la salud del hombre, tanto desde la creación de aparatos como su reciclaje, causando deterioro intelectual en niños y dañando el sistema nervioso, sanguíneo y reproductivo en adultos. También daña a los riñones $\mathrm{y}$, al someterlo a altas temperaturas, los humos del plomo afectan a casi todos los órganos.

Cadmio: es comúnmente utilizado en las baterías recargables de las computadoras, en los tableros de circuitos y semiconductores. Por lo general, el cadmio no se encuentra en el ambiente como un metal puro, sino como un mineral combinado con otros elementos como el oxígeno (óxido de cadmio), el cloro (cloruro de cadmio) o el sulfuro (sulfato o sulfuro de cadmio). Se extrae como producto secundario durante la producción de otros metales tales como el cinc, plomo o cobre. En Estados Unidos, la Agencia Internacional para la Investigación del Cáncer (IARC, por sus siglas en inglés) ha determinado, en el 2009, que el cadmio es carcinogénico para los seres humanos y la Agencia de Protección Ambiental (EPA, por sus siglas en inglés) ha establecido que, si se inhala, es probablemente un carcinógeno humano. 
Cobre: es uno de los mejores conductores de electricidad y uno de los pocos metales que pueden encontrarse en la naturaleza sin combinar con otros elementos. El cobre posee propiedades físicas, químicas, mecánicas y biológicas que propician su uso industrial en múltiples aplicaciones. En cuanto a su aplicación en las tecnologías informáticas, el cobre es el metal con mejor conductividad eléctrica y unida a su ductilidad y resistencia mecánica, tanto a la tracción como a la corrosión, lo han convertido en el material más empleado para fabricar cables eléctricos. Todos los equipos informáticos y de telecomunicaciones contienen cobre en mayor o menor medida en sus circuitos integrados, transformadores, cableado interno, en paneles de circuito impreso, producción de microchips y semiconductores. Justamente, en los equipos informáticos, los disipadores térmicos permiten diseminar las elevadas temperaturas que se concentran en los microprocesadores de alta frecuencia y en los dispositivos analógicos. Una de las principales propiedades del cobre es su habilidad para transmitir energía y datos simultáneamente, proporcionando una fuente confiable de energía que permite la utilización de dispositivos en red. Actualmente, los cables y conectores de cobre son usados en más del $80 \%$ de los equipos de interconexión y transportadores de señal en los centros de datos. En muchos casos, el cobre compite exitosamente contra la fibra óptica. ${ }^{6}$

Sin embargo, las reservas de cobre están por agotarse. La Organización para la Cooperación y el Desarrollo Económico calcula que hacia el 2030 ya no habrá reservas de cobre en el subsuelo; paradójicamente, de acuerdo con investigaciones, existen alrededor de 225 millones de toneladas de ese metal desperdiciadas en los basureros. ${ }^{7}$

Mercurio: que se utiliza en los monitores de pantalla plana como dispositivo de iluminación y en pilas primarias. Puede causar daños en el sistema nervioso central, particularmente en etapas tempranas de desarrollo. No hace falta exponerse a grandes dosis para enfermarse: la exposición en pequeñas cantidades puede causar daños al cerebro, nervios y sistemas reproductivos, a los pulmones, los riñones y otros órganos, y afectar al desarrollo fetal. También es tóxico para la vida acuática pudiendo de esta manera afectar la cadena alimenticia.

Níquel: utilizado en baterías, produce efectos sobre el

\footnotetext{
${ }^{6}$ Estos estudios están disponibles en COBRE. SALUD, MEDIO AMBIENTE Y NUEVAS TECNOLOGÍAS. (editorial) Copper Connects Life. (Fecha de acceso 30 de septiembre de 2016). 128pp. URL disponible en: http://www.ecosea.cl/pdfs/Cobre_Salud_Medio_Ambiente_Nuevas_Tecn ologias.pdf

${ }^{7}$ Estos datos se pueden consultar en SECRETARÍA DE MEDIO AMBIENTE Y RECURSOS NATURALES DE LA REPÚBLICA DE MÉXICO. 2014. Consumo Sustentable: Un Enfoque Integral. México: Semarnat, México. 25pp. ISBN: 978-607-8246-20-5
}

sistema respiratorio, alergias, irritación en ojos y piel y posiblemente es cancerígeno.

Litio: utilizado en baterías, ocasiona afecciones en el sistema nervioso, fallas respiratorias y nauseas. Según Greenpeace (2010), este mineral hoy en día gana adeptos en la mitigación del cambio climático y del calentamiento global, ya que es uno de los elementos primordiales en los aparatos electrónicos con bajo consumo energético. Sin embargo, los principales impactos ambientales en la extracción del litio no difieren en gran medida de la extracción de otros minerales: consumo, contaminación de agua, impactos en el paisaje, en la flora y la fauna cambios en los ecosistemas, generación de residuos sólidos y químicos, entre otros.

Berilio: ha sido recientemente considerado un elemento cancerígeno para el ser humano. La mayor parte de este mineral es usado en aleaciones (mezclas de metales) para la fabricación de componentes eléctricos o electrónicos, o como materiales para la construcción de maquinarias, automóviles y computadoras. En Estados Unidos, tanto el Departamento de Salud y Servicios Humanos (DHHS) como la Agencia Internacional para la Investigación del Cáncer han determinado en el Capítulo Reseña Toxicológica del Berilio de los Resúmenes de Reseñas Toxicológicas, 2002, que el berilio y sus compuestos son carcinogénicos en seres humanos.

Tierras raras: es el nombre común de 17 elementos químicos: escandio, itrio y los quince elementos del grupo de los lantánidos. La electrónica de última generación, los superconductores, las computadoras, los teléfonos celulares y los instrumentos LED, son solo algunos de los cientos de productos que utilizan minerales de tierras raras, los cuales están en peligro de desabastecimiento. Además, ayuda a mantener los teléfonos y las computadoras portátiles de un tamaño pequeño, ya que tiene un área de superficie muy alta cuando está hecho en forma de polvo (Chiou 2011). China extrae y produce aproximadamente el 95\% de los minerales de tierras raras en el mundo, y desde el 2010 ha reducido sus exportaciones. Japón, la Unión Europea y Estados Unidos han argumentado que las cuotas de China elevan el precio de los productos, mientras que China sostiene que está tratando de proteger el ambiente, al destinar menos tierras para los minerales de tierras raras.

"Gracias a estos metales podemos disfrutar de
electrodomésticos y dispositivos más pequeños. Sin ellos,
nuestros móviles no tendrían luz ni sonido; y un coche
incorpora aproximadamente once kilos de tierras raras.
Incluso están dentro de los billetes de euros", apunta
Ricargo Prego -citado por David Pérez- (Pérez 2014). 
En el 2013, la Academia Nacional de Ciencias de Estados Unidos publicó un estudio donde analizaba los 62 elementos químicos más utilizados por la industria tecnológica. Llegaron a la conclusión de que para al menos diez no existen reemplazos o todavía no se conocen. Entre ellos, se encontraron varias tierras raras.

En este mismo contexto, el plástico y la fibra de vidrio se utilizan en la construcción de las pantallas de LCD y tableros de circuitos eléctricos -entre otros-. El plástico, que se obtiene de la mezcla de petróleo, gas y sustancias químicas, utiliza para su producción recursos no renovables y escasos, y la extracción petrolera es considerada una actividad de riesgo y de alto impacto ambiental.

\section{Contaminación del agua potable}

El agua potable y limpia representa una cuestión de primera importancia, porque es indispensable para la vida humana y para sustentar los ecosistemas terrestres y acuáticos. Recordamos que en el mes de septiembre de 2000 los dirigentes de todos los países se comprometieron en la Cumbre del Milenio de las Naciones Unidas a reducir a la mitad para el año 2015 la proporción de personas que carecían de acceso al agua potable o que no podían costearla. Asimismo, en la Cumbre Mundial sobre el Desarrollo Sostenible de 2002, celebrada en Johannesburgo, se acordó un objetivo similar.

Conforme al Informe Conjunto de la Organización Mundial de la Salud y del Fondo de las Naciones Unidas para la Infancia, OMS/UNICEF 2012, basados en datos disponibles hasta el final de 2010, 783 millones de personas viven sin acceso al agua potable y 2000 millones no cuentan con los servicios mínimos de saneamiento.

No obstante, el derecho al agua es un derecho humano reconocido- implícita o explícitamente - en numerosos instrumentos internacionales y regionales (en Argentina con jerarquía constitucional, conforme el artículo 75 inciso 22 de la Constitución Nacional, ubicándose en el denominado bloque de constitucionalidad federal ${ }^{8}$ ), como la Declaración

${ }^{8}$ La frase bloque de constitucionalidad fue utilizada por primera vez por Louis Favoreau, para explicar la Decisión D-44, de 16 de julio de 1971, emitida por el Consejo Constitucional francés para referirse al bloque integrado por la Constitución francesa de 1958, la Declaración de 1789, el Preámbulo de la Constitución de 1946 y los principios fundamentales de las leyes de la República. Ver: Louis Favoreau, L. (1990) El bloque de constitucionalidad. Madrid, España: Civitas. En Argentina, la adoptó el Profesor Bidart Campos afirmando que: Por bloque de constitucionalidad puede entenderse, según cada sistema en cada estado, un conjunto normativo que parte de la constitución, y que añade y contiene disposiciones, principios y valores que son materialmente constitucionales fuera del texto de la constitución escrita. Suele situarse en ese bloque a los tratados internacionales, al derecho consuetudinario, a la jurisprudencia, etcétera. El bloque de constitucionalidad así integrado sirve para
Universal de Derechos Humanos, el Pacto Internacional de Derechos Económicos, Sociales y Culturales, la Convención sobre la Eliminación de todas las formas de Discriminación contra las Mujeres y la Convención sobre los Derechos del Niño.

En su Observación General No 15 , el Comité de Derechos Económicos, Sociales y Culturales (2002) aporta algunas precisiones sobre el contenido y fundamentación del derecho al agua:

"El derecho humano al agua es el derecho de todos a disponer de agua suficiente, salubre, aceptable, accesible y asequible para el uso personal y doméstico. Un abastecimiento adecuado de agua salubre es necesario para evitar la muerte por deshidratación, para reducir el riesgo de las enfermedades relacionadas con el agua y para satisfacer las necesidades de consumo y cocina y las necesidades de higiene personal y doméstica".

Posteriormente, el 28 de julio de 2010, a través de la Resolución 64/292, la Asamblea General de las Naciones Unidas reconoció explícitamente el derecho humano al agua $\mathrm{y}$ al saneamiento, reafirmando que un agua potable limpia y el saneamiento son esenciales para la realización de todos los derechos humanos.

En cuanto a la contaminación del agua potable producida por las tecnologías informáticas, la fabricación de computadoras y varios de sus componentes electrónicos y no electrónicos constituye un sector muy contaminante, con sustancias tóxicas tales como dioxinas, cadmio y plomo, además de consumir electricidad, materias primas, sustancias químicas y agua generando residuos peligrosos para la salud. Todo esto incrementa las emisiones de dióxido de carbono $\left(\mathrm{CO}_{2}\right)$ e impacta de forma directa o indirecta en el ambiente.

Una computadora es una construcción compleja que involucra una gran variedad de diversos componentes, a saber, el teclado, la Unidad Central de Procesamiento y la pantalla, hasta los que forman parte de los circuitos interiores, incluyendo tableros de cableado impreso (PWBs siglas en inglés de Printed Wiring Boards). Por lo general, es ensamblada usando miles de componentes manufacturados en plantas especializadas que pueden estar localizadas en un gran número de países, en consecuencia, su fabricación es verdaderamente una industria mundial en cuyo interior se diferencian una gran variedad de sectores.

La fabricación de PWBs y chips semiconductores requiere

acoplar elementos útiles en la interpretación de la constitución y en la integración de los vacíos normativos de la misma. Bidart- Campos 1998 p.276 
una serie de procesos altamente complejos y químicamente intensivos ya que utilizan grandes cantidades de sustancias químicas y agua, incluyendo los numerosos ciclos de enjuague, resultando una importante pérdida de metales y químicos que se incorporan en las aguas residuales. Aunque algunas plantas puedan recuperarlos, no todos los procesos para el tratamiento de tales aguas tienen la capacidad de eliminar muchos de los químicos utilizados, incluyendo metales pesados.

El ensamblaje de componentes individuales en dispositivos pequeños y el producto final puede requerir el uso de surfactantes y solventes químicos. Históricamente las soldaduras eran aleaciones de base plomo $\mathrm{y}$, aunque actualmente se están usando alternativas libres de plomo, se han acordado numerosos supuestos de aplicabilidad a fin de permitir el uso continuo de soldaduras de plomo.

\section{Generación de residuos o desechos peligrosos}

El sistema de cómputo como sus componentes contienen materiales tóxicos y los consumidores se deshacen de los viejos CPUs, monitores u otro equipamiento electrónico al año de su compra, y gran cantidad de estos componentes terminan contaminando la tierra $\mathrm{y}$, en muchos casos, el agua. $^{9}$

Aún durante este periodo de vida útil es muy probable que sea necesario realizar actualizaciones de componentes en las máquinas. Con el correr del tiempo, el software puede sufrir modificaciones correctivas, adaptativas y ampliaciones, relacionadas con el agregado de nuevas funcionalidades, que al modificar el código y documentación inicial van deteriorando su correcto funcionamiento.

Toda esta producción tecnológica genera toneladas de basura electrónica, también denominado internacionalmente E-Waste (del inglés electronic waste). En Europa también es conocido como RAEE- residuos de aparatos electrónicos y eléctricos- incorporando al concepto los residuos eléctricos. El E-Waste se refiere a todo producto, bien o componente que posee un dispositivo electrónico o chip, que ha llegado al término de su vida útil y está asociado a aparatos que son utilizados diariamente y en distintos ámbitos. (Martínez \& Porcelli 2015).

En el año 2002, la Red de Acción de Basilea (BAN) difundió un demoledor reporte titulado Exporting Harm: The High-tech Trashing of Asia, que mostraba la cruda realidad del reciclaje de la basura electrónica en China. La ciudad de Guiyu,

9 TECNOLOGÍA PARA CUIDAR EL MEDIO AMBIENTE. (editorial) Revista Claves 21 Ambiente y Desarrollo Sustentable. (Fecha de acceso 15 de julio de 2016) URL disponible en: http://claves21.com.ar/tecnologiaverde-herramientas-para-cuidar-el-medio-ambiente/ cercana a Hong Kong, se había convertido en un gigante vertedero de basura informática en el cual miles de personas, muchas de ellas niños y ancianos, realizaban prácticas peligrosas como quemar los cables de los ordenadores para obtener el cobre, o fundir circuitos en un cazo sobre el fuego para recuperar el plomo y otros metales (BAN 2002). Situaciones como ésta motivaron que el documento final de Río +20 incluyera la expresa exhortación a los países y a otras partes interesadas a la adopción todas las medidas posibles para prevenir la gestión irracional de los desechos peligrosos y su vertido ilícito (ONU 2012).

En la guía elaborada en el marco de una alianza de trabajo entre la empresa RECYCLA Chile S.A. y la Fundación Casa de la Paz titulada Residuos Electrónicos La Nueva Basura del Siglo XXI del 2007 se destaca que el impacto en el ambiente que comienza desde la etapa de fabricación, genera también una gran cantidad de residuos en la producción de cada unidad, denominado la carga ecológica, que en el caso de un computador es casi 1500 kilogramos, de un portátil, 400 kilogramos y de un teléfono móvil, 75 kilogramos.

A este respecto podemos señalar que en la mayoría de los países de la Unión Europea se aplica el principio de responsabilidad extendida del productor (REP); definida por LINDHQVIST, -citado por SILVA- como un

"principio de política ambiental que promueve el
mejoramiento total del ciclo de vida de los productos, por
medio de la extensión de las responsabilidades del
productor en varias etapas de dicho ciclo, especialmente al
devolver, recuperar y disponer el producto" (Silva 2010).

Este mecanismo induce a los proveedores a diseñar productos menos contaminantes y que a su vez faciliten el reciclado. Monteverde (2010) comenta que, en China, en agosto de 2008 se aprobó una norma que impulsa la responsabilidad extendida del productor en el reciclado y la disposición final del equipamiento. Estas legislaciones son anticipatorias al claro pronunciamiento del documento final de Río + 20 que señala que los desechos sólidos, como los desechos electrónicos y los plásticos, representan problemas particulares a abordar, solicitando la elaboración y aplicación de políticas, estrategias, leyes y reglamentos nacionales y locales amplios sobre la gestión de esos residuos. Si bien el reciclaje de los residuos electrónicos es un negocio lucrativo, muchos países carecen tanto de reglamentaciones específicas como de iniciativas empresariales, y son dejados al sector informal, lo que expone a miles de recicladores a graves riesgos de salud.

El estudio de la iniciativa "Solving the E-Waste Problem" 
(STEP), realizado por una alianza de las Naciones Unidas, empresas, gobiernos y organizaciones no gubernamentales, ha sido el primero en reflejar un mapa de residuos electrónicos por países. Además, promueve el reciclaje y la eliminación segura de piezas a menudo tóxicas. En el informe se menciona que el auge económico de países como China, India y Brasil ha contribuido a la acumulación de grandes cantidades de basura electrónica. Así, las estimaciones del mismo apuntan a que, para el año 2017, la basura electrónica se elevará a 65.4 millones de toneladas, teniendo como dato de referencia que, en 2013, se produjeron casi 48.9 millones de toneladas de estos residuos.

Agbogbloshie, situado en Accra (Ghana), es uno de los ejemplos más paradigmáticos de basurero tecnológico. Según el último informe realizado por la Green Cross Switzer landy el Blacksmith Institute existe en esta zona una contaminación por plomo, cadmio y otros contaminantes perjudiciales para la salud que supera en más de 50 veces los niveles libres de riesgo, y que convierten la zona en uno de los diez lugares más contaminados del planeta.

Otro de los basureros tecnológicos es el situado en Zimbabwe, del que ya se ha advertido podría causar crisis ambiental al no disponer de sistemas adecuados para eliminar sus residuos. Esto sucede a pesar de la existencia de tratados internacionales como la Convención de Basilea que restringe los movimientos transfronterizos de desechos. Todo se debe a que, conforme la visión de Martín-Peña (2014), sigue saliendo mucho más barato deshacerse de los desechos en algún lugar remoto que seguirlas normas de reciclaje impuestas en diferentes convenios y convenciones, tanto nacionales como internacionales.

\section{Dimensión social}

En la sociedad del consumo, las empresas, a través de las pautas publicitarias, inducen al consumidor a adquirir bienes y servicios que realmente no necesitan. Se generan, en forma inconsciente, necesidades y se impone el sentido de pertenencia. Es decir, adquirir bienes para "pertenecer" y se divide al mundo entre los seres humanos que tienen y los que no tienen. Esa inducción cultural del consumo hace que se confundan necesidades con deseos y en demandas culturalmente condicionadas, a través del desarrollo pautado de la innovación con salidas al mercado de productos que envejecen a los anteriores. Otro condicionante reside en la moda, en determinados modos de consumo que son reemplazados por nuevos, fenómeno cuyo icono es la indumentaria (Tambussi 2015).

Como consecuencia de tal comportamiento, el consumidor se sobre endeuda para adquirir bienes muchas veces suntuarios pero que percibe como imprescindibles.

Poco después de la Segunda Guerra Mundial, el analista de comercio minorista, Victor Lebow citado por Vance Packard (1968)-, describió lo que se necesitaba para mantener el consumo y las fábricas en marcha, al afirmar que la economía productiva exige que las personas hagan del consumo su forma de vida, que conviertan en ritos las compras y el uso de bienes y que busquen la satisfacción espiritual, emocional y del propio ego en el consumo. Concluye que es necesario que las cosas se consuman, se gasten, se reemplacen y se descarten a un ritmo de aceleración continua.

Las grandes empresas se aseguran hoy sus ganancias a expensas de los consumidores creándoles la estructura mental adecuada para la venta de sus productos, imponiéndoles, de hecho, las condiciones contractuales unilateralmente predispuestas y disfrutando de su inexperiencia e ignorancia jurídica, mercantil y financiera. Paralelamente, la eliminación de la competencia, mediante la monopolización del mercado, condena a los consumidores a no poder optar entre varias ofertas alternativas, condicionando su libertad de elección (Stiglitz 1983).

Hoy en día, la presión por comprar cosas más nuevas y más sofisticadas, se vincula a la presión de expresar el status social. En el libro "The Bridge at the Edge of the World" Speth (2008) asegura que los psicólogos observan que las personas están predispuestas a encontrar seguridad mediante dos actitudes: sobresalir y encajar. La sociedad capitalista, el consumo y la mercantilización hacen hincapié en ambas, por eso se gastan más rápido las cosas visibles, desde afuera, que las que se consumen en privado.

De esta forma, los consumidores empiezan a valorar otras cualidades de los productos, más basadas en el consumismo y en la moda que en las cualidades de duración, dejando a un lado valores como la resistencia al tiempo. Se adquieren productos no siempre por necesidad sino para exhibirse y el consumidor tendrá la necesidad impuesta de renovar sus electrodomésticos estropeados, o bien, de sumarse a las tendencias consumistas de la moda para actualizar su celular o todo tipo de artículos. Nace la cultura de desechar, de reemplazar. Desaparece la cultura de reparar.

Desde la Iglesia Católica, en la Encíclica Laudato Si, también se alerta sobre la visión consumista del ser humano, alentada por los engranajes de la actual economía globalizada, que tiende a homogeneizar las culturas y a debilitar la inmensa variedad cultural, que es un tesoro de la humanidad. La imposición de un estilo hegemónico de vida 
ligado a un modo de producción puede ser tan dañina como la alteración de los ecosistemas.

\section{Dimensión Económica}

En términos macroeconómicos se dice que la economía de un país crece cuando su consumo y producción aumentan, pues ambos aspectos son interdependientes. Las políticas de crecimiento fomentan la demanda de productos, por lo cual, los consumidores son el motor de la economía.

Entre otros factores, un país se considera desarrollado cuando la mayoría de su población pertenece a la clase media, porque una de sus características es que los ingresos que percibe le permiten consumir más bienes y servicios de los estrictamente necesarios para vivir. En otras palabras, la clase media es la esencia del desarrollo.

En consecuencia, la obsolescencia programada es una fórmula más dentro de la sociedad de consumo que beneficia tanto a las empresas -asegurándoles rentabilidad y una constante demanda de su producción- como al sistema financiero, que justifica su existencia al otorgar créditos para el consumo. Sin embargo, el gran perjudicado es el consumidor ya que al provocar el hiperconsumo, es decir, comprar y contratar en exceso por encima de la necesidad del cliente, le produce la necesidad de desembolsar dinero nuevamente para reemplazar el producto. La voluntad de ahorrar, por tanto, a veces no es suficiente. Esto le ocasiona al consumidor un perjuicio económico importante y además crea también la sensación de angustia, de frustración en alguien que ha hecho una gran inversión en la compra de un producto tecnológico y que se queda obsoleto rápidamente.

La obsolescencia programada se vuelve cada vez más sofisticada. Muchas marcas, no conformes con fabricar productos de baja calidad y rápidamente perecederos, recuerdan constantemente que es imprescindible cambiar esos productos por otros nuevos para poder garantizar la eficacia de los mismos. Por otra parte, los fabricantes de productos como computadoras, cámaras digitales o móviles (por citar algunos ejemplos), no sólo fabrican productos casi obsoletos en el momento en que los compramos, sino que, ni siquiera ofrecen la posibilidad de sustituir piezas para repararlos, prolongar su vida o alcanzar a los nuevos modelos. A esto se le suma la poca mano de obra especializada en materia de reparaciones, que hace muchas veces antieconómico el arreglo, cuando no totalmente inútil. Es más rentable, por supuesto, para el productor y más barato, en muchos casos, para el consumidor comprar uno nuevo. En el mercado informático, además, se lanzan nuevos softwares, ya diseñados en el momento de proyectar los anteriores, que no soportan nuestros viejos dispositivos. Desde otro ángulo, la Encíclica Laudato Si presenta un fuerte reclamo al sistema económico mundial basado exclusivamente en la tecnología. Los poderes económicos que continúan justificando el actual sistema mundial, donde priman la especulación y la búsqueda de la renta financiera, tienden a ignorar los efectos sobre la dignidad humana y el ambiente. La alianza entre la economía y la tecnología termina dejando afuera lo que no forme parte de sus intereses inmediatos, en consecuencia, la degradación ambiental, la degradación humana y ética están íntimamente unidas.

Actualmente lo único que le interesa al mundo globalizado es extraer todo lo posible de las cosas olvidando -o en el mejor de los casos ignorando- la realidad misma de lo que tiene delante: la limitación de los bienes del planeta.

En consecuencia, la técnica tiene una inclinación a buscar que nada quede fuera de su férrea lógica, la cual no se dirige ni a la utilidad ni al bienestar, sino al dominio; el dominio, en el sentido más extremo de la palabra. La economía asume todo desarrollo tecnológico en función del crédito, sin prestar atención a eventuales consecuencias negativas para el ser humano.

Dentro de esta lógica, todo (incluso la naturaleza) debe servir para algo y tiene que ser útil a la producción de capital, transformando la vida en un mundo más de medios que de fines, desechando todo lo que se vincule con algún fin último. En los últimos 30 años, según Vilchis-Onofre et al. (2016) con una visión crítica de la dinámica capitalista servil a la acumulación del despojo, evidencia esta desposesión a través de una serie de políticas, que se encargan esencialmente de privatizar bienes naturales: mercantilizando agua, tierra, medios de comunicación, transporte, banca, seguridad social, educación, empleo e incluso, la cultura.

\section{AVANCES: DIFERENTES ALTERNATIVAS PROPUESTAS}

En el frontispicio del templo de Apolo en Delfos, los sacerdotes grabaron dos preceptos: "Conócete a ti mismo" y "Nada en exceso", enseñanzas hoy vigentes, pero al parecer olvidadas por todos.

La destrucción de la naturaleza, producto de los modernos patrones de producción y consumo, y sus consecuencias para la humanidad, son cada vez más evidentes. Más allá de sus impactos con temas aislados anteriormente analizadoscontaminación del aire, agua, suelo, desertificación o 
generación de residuos- el eje común está en que estas formas de producción rompen la relación hombrenaturaleza, dejando de lado la dependencia con ella para la vida y considerándola exclusivamente materia prima del ciclo económico, desnaturalizándola para insertarla en el mercado, convirtiéndola en mercancía.

Para Carlos Magariños, experto en sustentabilidad y CEO de Prospectiva 2020, en 2007 el sistema de producción de la tierra consumió una vez y media los recursos naturales del planeta a su tasa normal de reproducción anual. Sin embargo, en proyección a 2030 se necesitarán dos planetas y medio, por lo que claramente el tema de la sustentabilidad será el tema del milenio y va a generar una revolución en todo lo relacionado con producción y consumo. Esta revolución supondrá la aparición y el desarrollo de nuevas tecnologías, afectará profundamente los patrones de producción y dará origen a un nuevo sistema de fijación de precios (Avellaneda 2011).

En este sentido, los científicos continúan en la búsqueda de diversas alternativas que no dañen el ambiente, poniendo énfasis en tecnologías que sean limpias y, por consiguiente, que frenen o al menos minimicen los impactos negativos. En consecuencia, tanto las políticas gubernamentales como las prácticas de gestión del sector público y privado, así como las opciones de tecnología y las inversiones deberán poner mayor énfasis en la eficiencia de los recursos, con el fin de ofrecer una mayor producción por unidad de insumo, así como reducir los daños ambientales. Es necesario cambiar los patrones actuales de producción y de consumo que fomentan una producción insostenible y la degradación de los recursos hacia un consumo responsable, a un cambio en los estilos de vida, un crecimiento económico que evite la degradación de los recursos y promueva un uso más eficiente de los recursos a través del enfoque de gestión de ciclo de vida que también reduce la contaminación y evita que simplemente se trasladen las cargas de un punto a otro de la cadena de suministro. No se trata necesariamente de consumir menos sino en consumir mejor, es decir, de manera más eficiente, reduciendo los riesgos para la salud y para el ambiente.

Tal y como se acordó en la Conferencia de las Naciones Unidas sobre el Desarrollo Sostenible de Rio +20 para lograr el desarrollo sostenible mundial deben producirse cambios fundamentales en la manera en que las sociedades producen y consumen. Todos los países deben fomentar modalidades de consumo y producción sostenibles.

Recordando las palabras de Albert Camus, en el discurso que pronunciara cuando le otorgaron el premio Nobel de Literatura, en Estocolmo 1958, sostuvo que;

\begin{abstract}
"Indudablemente cada generación se cree destinada a rehacer el mundo. La mía sabe, sin embargo, que no podrá hacerlo. Pero su tarea es quizás mayor. Consiste en impedir que el mundo se deshaga" (Camus 1958) ${ }^{10}$.
\end{abstract}

Con conceptos similares, el Papa Francisco, en la Carta Encíclica Laudato Si afirma:

"La cultura ecológica no se puede reducir a una serie de respuestas urgentes y parciales a los problemas que van apareciendo en la degradación del ambiente, al agotamiento de las reservas naturales y a la contaminación. Debería ser una mirada distinta, un pensamiento, una política, un programa educativo, un estilo de vida. Buscar sólo un remedio técnico a cada problema ambiental que surja es aislar cosas que en la realidad están entrelazadas y esconder los verdaderos y más profundos problemas del sistema mundial" (Francisco 2015).

A continuación enumeraremos las diferentes alternativas propuestas que han buscado desarrollar un nuevo modelo que permita propiciar una cultura altamente sustentable y respetuosa del ambiente en lo que concierne a la gestión de los recursos naturales, a la eliminación de la práctica empresarial de la obsolescencia planificada, al incremento de la eficiencia de la energía, a la reducción de las emisiones de gas carbono, al desarrollo de productos y servicios verdes, a la gestión de desperdicios y a la utilización de tecnologías altamente limpias.

\section{Legislación y jurisprudencia}

La lucha contra todos los tipos de obsolescencia programada obtuvo su primer logro legislativo. El Parlamento francés, dentro de la llamada Ley de Transición Energética, penalizó a las empresas con multas de hasta $300.000 €$ y a los empresarios, con penas de hasta dos años de prisión cuando, con la excusa de las leyes del mercado y la supervivencia empresarial, violasen las leyes de defensa del consumidor. La iniciativa partió, en el 2014, del senador Jean Vincent Placé, de la formación política de Les Verds- Los Verdes-, argumentando que la obsolescencia programada era nociva para el medio ambiente, la sostenibilidad y componía un engaño para el consumidor. La misma atacaba la estrategia de concebir un producto con el propósito deliberado de acortar su vida potencialmente útil, bien sea por la introducción de un defecto, una pieza frágil, una

${ }^{10}$ Estas palabras fueron expresadas por el autor en 1958 en su alocución en oportunidad de recibir el Premio Nobel, pero el texto fue tomado de un capítulo escrito por Camus en un libro publicado en 1994, el cual es citado en las referencias. 
parada programada, una incompatibilidad o cualquier otra estratagema tramposa. Estas medidas completarán la Ley de Consumo actual francesa y pretenden erigirse como un modelo para otros países europeos. Así introduce como castigo penal la obsolescencia programada al considerar que consiste en acortar la vida útil de un producto intencionadamente para que el consumidor tenga que comprar uno nuevo, limitando su periodo de uso por razones del modelo económico. Entonces, aquel que cometa ese delito será castigado con una pena máxima de dos años de prisión y 300.000 euros de multa, en virtud de un nuevo artículo L 213-4-1, recogido en el Código de Consumo. Se prevé exactamente el mismo tratamiento que en el caso de las prácticas comerciales engañosas. La norma francesa recoge todas las variantes de obsolescencia programada, pero su aplicación no será fácil. ¿Cómo demostrar que se ha introducido un defecto deliberadamente? La industria, de hecho, siempre ha negado esta práctica, pese a que es evidente que los electrodomésticos han acortado su vida útil. ${ }^{11}$

Un año antes, Europa comenzaba a abordar el problema. El Comité Económico y Social Europeo (Cese), órgano consultivo de la Unión Europea, aprobó, en 2013, un dictamen que exige la prohibición total de la obsolescencia programada, con el fundamento que, si se desecharan menos componentes electrónicos y se repararan más, se crearían miles de empleos, algo necesario en la economía actual. El dictamen también propone que las empresas faciliten la reparación, campañas de sensibilización sobre la obsolescencia estética que se encuentra atada a las modas, y por último la implantación de un sistema de etiquetado que informe al consumidor si prefiere un producto barato $u$ otro más caro, pero más duradero. Esta última medida, sería similar a la ya implementada sobre eficiencia energética, pero es una dura tarea debido a que es imposible prever la duración de un producto ya que no se puede controlar el uso que se va a hacer de éste.

En Alemania, el partido de Los Verdes presentó un estudio y propuso algunas soluciones, mientras en Bélgica se adoptaba una resolución al respecto en el Senado. Además, Les Verds, la única candidatura ecologista que se presentó a las elecciones catalanas, promoverá una Ley catalana contra la Obsolescencia Programada, incluyendo en su programa electoral como prioridad la eliminación de tal práctica.

${ }^{11}$ Para ampliar se puede consultar en FRANCIA PLANTA CARA A LA OBSOLESCENCIA PROGRAMADA CON PENAS DE CÁRCEL Y MULTAS DE 300.000 EUROS. (editorial) 2014. El Economista.19 oct 2014 (Fecha de acceso el 14 de marzo de 2016) URL Disponible en: http://www.eleconomista.es/internacional/noticias/6171070/10/14/Fran cia-planta-cara-a-la-obsolescencia-programada-con-penas-de-carcel-ymultas-de-300000-euros.html
Siguiendo similar camino, el 26 de febrero de 2015, la Secretaría Nacional de Educación Superior, Ciencia, Tecnología y Educación de Ecuador actualizó la página web colaborativa de su proyecto de ley (este Estado construye su legislación de esa manera mediante ese tipo de páginas conocidas en la jerga informática como "Wiki"). El código propuesto, tiene por objetivo establecer el conocimiento como un bien de interés público para la sociedad, así como desarrollar las reglas básicas para la carrera del investigador y la creación y funcionamiento de los espacios en los que se genera conocimiento e innovación.

Dentro de las disposiciones generales del código, conforme Delgado 2015, se puede leer una referencia a la obsolescencia programada, en la décima disposición la cual obliga a las instituciones públicas a realizar un control aleatorio de sus bienes ex post a la adquisición, para verificar que éstos no sufran de obsolescencia programada.

A los efectos de aplicación de esta norma se entenderá como obsolescencia programada el conjunto de técnicas mediante las cuales un fabricante, importador o distribuidor de bienes, en la creación o a través de la modificación del producto, reduce deliberadamente e injustificadamente su duración con objeto de aumentar su tasa de reemplazo.

En los casos en los que se determine la existencia de obsolescencia programada, los proveedores de dichos bienes quedarán impedidos para contratar con el Estado de manera permanente, sin perjuicio de la responsabilidad civil y las sanciones administrativas y penales a las que hubiere lugar en aplicación de la Ley Orgánica de Defensa del Consumidor, la Ley Orgánica de Control del Poder del Mercado y el Código Integral Penal, respectivamente.

Se generarán los mismos efectos señalados anteriormente cuando se compruebe, a través de los órganos correspondientes, la obsolescencia programada en el comercio entre particulares.

En forma indirecta, la Directiva Europea 2005/29/CE del Parlamento Europeo y del Consejo, del 11 de mayo de 2005, relativa a las prácticas comerciales desleales de las empresas en sus relaciones con los consumidores en el mercado interior, fue aplicada, en Italia, en un caso jurisprudencial para condenar la obsolescencia programada, que comentaremos a continuación. La Directiva tiene por objeto proteger los intereses económicos de los consumidores antes, durante y después de efectuar una transacción comercial. Define dos categorías específicas de prácticas comerciales desleales: prácticas engañosas-por acción o por omisión- y prácticas agresivas. En cuanto a las prácticas 
comerciales engañosas, diferencia acciones engañosas de omisiones engañosas. Las primeras suponen toda práctica comercial que contiene información falsa o que carezca de veracidad, o si la información, aun cuando sea correcta, puede inducir a error al consumidor medio y hacerle tomar una decisión sobre una transacción que de otro modo no hubiera tomado, incluyendo información falsa o engañosa sobre la existencia o la naturaleza del producto, las características principales del producto (su disponibilidad, sus beneficios, sus riesgos, su composición, su origen geográfico, los resultados que pueden esperarse de su utilización, etc), el alcance de los compromisos del comerciante, el precio o la existencia de una ventaja específica con respecto al precio y la necesidad de un servicio o de una reparación. Por otra parte, las omisiones engañosas se producen cuando se omite o se ofrece de manera poco clara, ininteligible, ambigua o en un momento que no es el adecuado la información sustancial que necesita el consumidor medio, según el contexto, para tomar una decisión sobre una transacción, lo que, en consecuencia, hace o puede hacer que el consumidor tome una decisión sobre la compra que de otro modo no hubiera tomado. ${ }^{12}$

En Argentina, el Código Civil y Comercial (vigente a partir del 1 de agosto de 2015 y ámbito de aplicación nacional ${ }^{13}$ ), en el Libro Tercero ("Derechos Personales") Título III ("Contratos de Consumo") Sección 2a ("Información y publicidad dirigida a los consumidores"), el artículo 1100, titulado "Información" obliga al proveedor a suministrar al consumidor información respecto de las características esenciales de los bienes y servicios que provee. El contenido de dicha información deberá referirse a las características esenciales de los bienes y servicios, las condiciones de comercialización y toda otra circunstancia que pueda ser objetivamente relevante para que su destinatario pueda evaluar la conveniencia o no de adquirir el bien o servicio del que se trate. Se trata de posibilitarle tomar una decisión ponderada, con base en información clara y suficiente que le permita razonablemente formar un juicio de valor. Este deber de información adquiere en materia de defensa del consumidor el rango de derecho fundamental reconocido expresamente en el artículo 42 de la Constitución de la Nación Argentina. De acuerdo a Lorenzetti (2015), el

${ }^{12}$ Esta es una breve síntesis de la Directiva la cual se puede consultar en UNIÓN EUROPEA. UE. 2005. Directiva 2005/29/CE del Parlamento Europeo y del Consejo, de 11 de mayo de 2005, relativa a las prácticas comerciales desleales de las empresas en sus relaciones con los consumidores en el mercado interior (Diario Oficial de la Unión Europea, L.149, de 11-05- 2005, pp. 22-39)

${ }^{13}$ La normativa nacional tiene jerarquía superior al ordenamiento jurídico provincial, conforme el artículo 5 y 31 de la Constitución Nacional Argentina. Las provincias tienen autonomía de primer grado, están facultadas a dictas sus propias normas, pero éstas deben ser conformes a la legislación nacional argentina. fundamento del deber de información está dado por la desigualdad que presupone que sólo una de las partes se encuentra informada sobre un hecho que puede gravitar o ejercer influencia sobre el consentimiento de la otra, de tal modo que el contrato no hubiera llegado a perfeccionarse o lo habría sido en condiciones más favorables.

A su vez, en el artículo 1101 ("Publicidad") prohíbe toda publicidad cuando el mensaje sea engañoso por omisión, por error o, peor aún, por deliberada falsedad, y que pueda inducir a contratar a quien de haber sido destinatario de una información veraz, no lo habría hecho; o provoca la frustración del interés que el consumidor tenía legítimamente derecho a esperar del bien o servicio objeto del contrato o importa una peligrosa tergiversación del equilibrio de mercado, con insalvable detrimento de los intereses individuales y colectivos. Como bien señala Rubén Stiglitz, (comentando dicho artículo en Herrera et al. 2015a) la publicidad existe para informar, pero fundamentalmente para persuadir. Por la publicidad se venden bienes y servicios, convirtiéndolos previamente en sueños y en imágenes. Su importancia en una economía de mercado es enorme, su finalidad actualmente es mucho mayor a vender determinados bienes, es mucho más sutil, "como el arte de enseñar a la gente a necesitar cosas" (Stiglitz 2015).

Del juego de estos artículos podemos inferir que los mismos pueden válidamente aplicarse a la obsolescencia programada, y, para cerrar el círculo, en todo sistema jurídico, debe observarse el principio de buena fe, consagrado en materia contractual, en el artículo 961 "Buena $f e$ ". La considerada es la buena fe-confianza o buena felealtad, que debe ser evaluada según un estándar objetivo medio, el de "un contratante cuidadoso y previsor". La buena fe exige hablar claro, no ocultar información necesaria para la deliberación y requerir también la información que se considere necesaria para el propio discernimiento. Este deber de información puede definirse de manera general como la obligación de la parte de poner en conocimiento de la otra las cualidades o vicios de la cosa objeto del contrato. (Medina \& Rivera 2014).

También existen precedentes judiciales en contra de la obsolescencia programada. Además del anteriormente comentado caso de las baterías de litio contra Apple, en Italia se interpuso una denuncia ante la Autorità Garante della Concorrenza e del Mercato, máxima autoridad encargada de la protección del consumidor en ese país, porque Apple estaba violando la normativa sobre el término de las garantías que cobija a toda la Unión Europea. Según el texto aprobado por el Parlamento Europeo, cualquier producto se encuentra respaldado por una garantía mínima de dos años, cosa que era ignorada por la compañía al vender un programa de 
protección extendida llamado AppleCare que funcionaba como una ampliación de la garantía, que según los documentos incorporados en su producto era de un año. En otras palabras: Apple vendía el segundo año de protección haciéndole creer a sus clientes que sus artefactos estaban cubiertos sólo por un año, lo cual le hizo merecedora de una fortísima sanción de $900.000 €$. La argumentación jurídica se basó en que Apple cometió una unfair business-to-consumer commercial practice in the internal market -una práctica comercial injusta de empresa a consumidor en el mercado interno-conocida como omisión engañosa, prohibida y castigable de acuerdo con la Directiva 2005/29/EC, la que dispone que es engañosa toda práctica comercial si se omite información que el consumidor promedio necesita para tomar una decisión transaccional informada y de ese modo causa o es probable que cause que el consumidor promedio tome una decisión que de otra manera no habría tomado. La sanción fue apelada por Apple ante el Tribunale Amministrativo Regionale del Lazio, pero sus pretensiones no prosperaron y la multa fue confirmada en segunda instancia el 22 de marzo de 2012. Este precedente se extendió por todo el Viejo Continente y fueron varias las organizaciones que han seguido el ejemplo de Italia. Así pues, en España la fundación para la protección del consumidor FACUAConsumidores en Acción- logró una resolución que sancionó a Apple por la misma razón con 47.000€. Mientras tanto, agrupaciones similares en Bélgica y Portugal tienen sus acciones todavía tramitándose en la jurisdicción. Chacón-Tapias (2014), nos ilustra con otro precedente en Brasil, donde el Instituto Brasileiro de Direito da Informática, radicó una Ação Civil Coletiva para a Defesa de Interesses Individuais Homogêneos ante la jurisdicción civil del Distrito Federal de Brasilia con el objeto de castigar a Apple por obsolescencia psicológica. En el litigio se dejó en claro cómo en un lapso inferior a cinco meses desde el lanzamiento del Nuevo iPad, la compañía introdujo la cuarta generación del dispositivo, el cual no tenía cambios considerables de ningún tipo ya que sus características eran técnicamente iguales a su antecesor, pero dejó obsoletos a los ojos de los consumidores a millones de ejemplares vendidos y causó un descontento generalizado por parte de los clientes.

\section{Ecoeficiencia, consumo y producción sustentable}

Las prácticas empresariales y productivas basadas en la ecoeficiencia, el consumo y la producción sustentable son los grandes aliados en la lucha contra la obsolescencia programada y psicológica o percibida. El concepto de ecoeficiencia, presentado por ForFas, 2011 -organización irlandesa dedicada a promulgar y desarrollar iniciativas para la creación y sustentabilidad de organizaciones verdes-, nace de la concepción global de los impactos ambientales de las diferentes fases del ciclo de vida de un producto y de la voluntad de reducir los diferentes efectos ambientales negativos. La World Business Council for Sustainable Development (WBCSD) lo define como:

"proporcionar bienes y servicios a un precio competitivo, que satisfaga las necesidades humanas y la calidad de vida, al tiempo que reduzca progresivamente el impacto ambiental y la intensidad de la utilización de recursos a lo largo del ciclo de vida, hasta un nivel compatible con la capacidad de carga estimada del planeta"14

La ecoeficiencia se halla estrechamente ligada al desarrollo sostenible ya que equivale a optimizar tres objetivos: crecimiento económico, equidad social y valor ecológico. Significa añadir cada vez más valor a los productos y servicios, consumiendo menos materias primas, generando cada vez menos contaminación a través de procedimientos ecológica y económicamente eficientes y previniendo los riesgos, quitando del mercado los productos que son poco eficaces y que son más contaminantes. ${ }^{15}$

El rediseño de procesos organizacionales es otro de los elementos que puede contribuir en la reducción del cambio climático y de la emisión de carbono. Rediseñar procesos implica simplificar tareas dentro de un proceso específico, crear una conciencia de economía, de energía, no solo de tipo de consumo, sino también asociada a los aspectos humanos.

A nivel regional, específicamente en el MERCOSUR ${ }^{16}$, el Decreto No 1289/2010 internalizó la Decisión del Consejo Mercado Común $\mathrm{N}^{\circ} 26$ del 28 de junio de 2007, en virtud de la cual se introdujo en la legislación argentina, con jerarquía

\footnotetext{
14 Ver FUNDACIÓN FORUM AMBIENTAL. Guía para la Ecoeficiencia. (Fecha de acceso 25 de noviembre de 2014) URL disponible en: http://www.forumambiental.org/pdf/guiacast.pdf

${ }^{15}$ Para mayor información ver: PORCELLI, A. \& MARTíNEZ, A. 2016. La Nueva Economía del Siglo XXI: análisis de los impactos de la Informática en el Ambiente. Tendencias Actuales en Tecnologías Informáticas Verdes, un compromiso con la Sustentabilidad" Revista Quaestio Iuris 4, (8) Número Especial (2015): 2174-2208

${ }^{16}$ El MERCOSUR fue creado por el Tratado de Asunción de 1991 entre Argentina, Brasil, Uruguay y Paraguay y en fases posteriores se han incorporado Venezuela y Bolivia, este último se encuentra en proceso de adhesión, con el objeto de logar la libre circulación de bienes, servicios y factores productivos, el establecimiento de un arancel externo común y de una política comercial común respecto a terceros Estados, la coordinación de políticas macroeconómicas y sectoriales y el compromiso de armonizar sus legislaciones. Básicamente, la estructura institucional del MERCOSUR está organizada por el Protocolo Adicional al Tratado de Asunción sobre la Estructura Institucional del Mercosur de 1994-Protocolo de Ouro Preto de 1994-. Los órganos con capacidad decisoria, de naturaleza intergubernamental del MERCOSUR son: el Consejo del Mercado Común, el Grupo Mercado Común y la Comisión de Comercio del MERCOSUR.
} 
supralegal pero infraconstitucional ${ }^{17}$, una norma en materia de "Politica de Promoción y Cooperación en producción y consumo sostenible", adaptada de la "Propuesta en el Simposio de Oslo en 1994" y adoptada por la "Tercera sesión de la Comisión para el Desarrollo Sustentable (CSD III) en 1995".

El artículo $1^{\circ}$ define producción sostenible (PS), en el inciso b) como aquella que integra sistémicamente las variables económicas, ambientales y sociales en la producción de bienes y servicios y consumo sostenible (CS), en el inciso c), como el uso de bienes y servicios que responden a necesidades del ser humano y proporcionan una mejor calidad de vida y al mismo tiempo minimizan el uso de recursos naturales de materiales peligrosos y la generación de desperdicios y contaminantes sin poner en riesgo las necesidades de las generaciones futuras. Para implementar esta política, los Estados Partes tendrán en cuenta el desempeño ambiental como estrategia de mejora de la competitividad y eficiencia de los sectores productivos; la optimización del uso de recursos naturales, materias primas e insumos; la sustitución de materiales por otros menos contaminantes, minimizando emisiones y residuos; la implementación y aplicación de metodologías y tecnologías ambientales preventivas; y el desarrollo de productos y servicios que generen el menor impacto ambiental, mejoren la equidad social y promuevan la prosperidad económica. A su vez, para lograr estos objetivos, las Partes deberán generar los instrumentos adecuados que faciliten la complementariedad entre las políticas productivas y ambientales del MERCOSUR; deben estimular la cooperación público-privada en la implementación de procesos de producción y consumo sostenibles; promover la incorporación de prácticas de producción y consumo sostenibles en los ámbitos público y privado; fomentar la innovación en el diseño y el desarrollo de productos y servicios que generen el menor impacto ambiental, mejorar la equidad social y promover la prosperidad económica; fortalecer la educación sobre patrones de producción y consumo sostenibles; facilitar el acceso a la información en producción y consumo sostenibles y promover una actitud preventiva, social y ambientalmente responsable del sector productivo. ${ }^{18}$

\footnotetext{
17 Conforme el artículo 75 inciso 22 y 24 de la Constitución de la Nación Argentina, los tratados internacionales de integración y las decisiones emanadas de los órganos por ellos creados tienen jerarquía supra legal. En igual sentido, el Código Civil y Comercial de la Nación Argentina dispone que los tratados internacionales tienen jerarquía superior a las leyes nacionales

${ }^{18}$ Toda la normativa se encuentra en MERCOSUR. Política de Promoción y Cooperación en Producción y Consumo Sostenibles en el MERCOSUR.2007. MERCOSUR/LXVIII CMC/P.DEC. No 26/07 Anexo Artículo 1 b) y c) 28 jun 2007, Asunción. (Fecha de acceso 9 de septiembre de 2016) URL disponible

http://www.ambiente.gov.ar/archivos/web/MERCOSUR/File/SGT\%206\%20Ordin
}

El Código Civil y Comercial Argentino, en el Título III ("Bienes"), Sección $3^{\text {a }}$ ("Bienes con relación a los derechos de incidencia colectiva"), artículo 240 ("Límites al ejercicio de los derechos individuales sobre los bienes") exige que el ejercicio de los derechos individuales sea compatible con los derechos de incidencia colectiva y que no afecten el funcionamiento ni la sustentabilidad de los ecosistemas de la flora, la fauna, la biodiversidad, el agua, los valores culturales y el paisaje. Los límites sociales y ambientales se plasman, por ejemplo, en el caso del derecho de propiedad que presenta una indudable función ambiental, que nace de la función social, pero se eleva, como elemento integrante de la propiedad, de forma independiente respecto de los planos individual y social (Herrera et al. 2015b).

El desarrollo sustentable se vincula a la noción de "consumo sustentable", receptado expresamente en el artículo 1094 del Código Civil y Comercial Argentino. Dicho artículo dispone que la interpretación de las normas que regulan las relaciones de consumo debe ser conforme con el principio de protección al consumidor y el de acceso al consumo sustentable. El consumo sustentable, entendido como el uso de servicios y productos que responda a las necesidades básicas y traiga mejor calidad de vida, minimizando el uso de los recurso naturales y materiales tóxicos y la emisión de desperdicios y contaminantes durante el ciclo de vida del servicio o producto, de manera de no poner en peligro la satisfacción de las necesidades de las generaciones futuras, constituye una parte esencial del desarrollo sustentable.

El artículo consagra entonces una cláusula general importantísima, porque cuando se debe proteger el derecho individual de acceso al consumo, se debe también encontrar un límite armónico en la sustentabilidad de los ecosistemas (Lorenzetti 1998).

Podemos afirmar que el consumo sostenible es una nueva forma de consumir, que se opone al consumismo, implica un nuevo consumidor: responsable, solidario y consciente de sus acciones y de la posibilidad de incidir en los hábitos sociales, económicos y ambientales. El consumo sustentable, según palabras de Cafferatta (2014), es a la vez consumo crítico -que se pregunta por las condiciones sociales y ecológicas en las que ha sido elaborado un bien o un servicio y exige calidad al mismo tiempo- y consumo ético.

Por su parte, la Encíclica Laudato Si, nos enseña que comprar es un acto moral no sólo económico y los consumidores también somos responsables en el control de las formas de producción de las empresas. Podemos, modificando los

aria\%20XL/Anexo-IV-RO-XLPolitica-Produccion-Cons-ROXL.pdf 
hábitos de consumo, forzarlas a producir de otra manera, dejando de adquirir ciertos productos nocivos para el ambiente, preferir los eco-sellados y así, al afectar el rédito de las empresas, se influye en el comportamiento de las mismas.

En Río+20, los dirigentes mundiales aprobaron el Marco Decenal de Programas para el Consumo y la Producción Sostenibles (siglas en inglés, 10YFP). También reconocieron el consumo y la producción sostenibles como preocupación universal y que los países desarrollados deben asumir el liderazgo en la promoción del cambio hacia patrones sostenibles de producción y consumo. El Marco Decenal de Consumo y la Producción Sostenibles es un marco de acción global para promover la cooperación internacional a fin de acelerar la transición hacia el consumo y producción sostenibles, tanto en países desarrollados como en desarrollo. Este marco apoya la creación y fortalecimiento de capacidades, facilita el acceso a asistencia técnica y financiera a los países en desarrollo, desarrolla, replica y amplia tales iniciativas tanto a nivel nacional como regional; contribuye así al incremento neto de las actividades económicas, a la erradicación de la pobreza y el desarrollo social. Los Objetivos principales del Marco Decenal consisten en apoyar políticas e iniciativas regionales y nacionales para acelerar la transición hacia el consumo y la producción sostenibles, creando así nuevas oportunidades de empleo/mercado y contribuyendo a la erradicación de la pobreza y el desarrollo social; integrar el consumo y la producción sostenibles en las políticas, programas y estrategias de desarrollo sostenible; facilitar la asistencia financiera y técnica y el intercambio de información $y$ conocimientos sobre herramientas, iniciativas y buenas prácticas. ${ }^{19}$

En la octava Reunión del Consejo Regional de América Latina y El Caribe sobre Consumo y Producción Sostenibles (CPS): acelerando la implementación regional del Marco Decenal de Programas de CPS, el 4 y de 5 de mayo de 2015, en Panamá, los Estados elaboraron varias propuestas de acción para la Secretaria y el Consejo Global del Marco Decenal de Programas de Consumo y Producción Sostenibles (10YFP).

La Agenda 2030 para el Desarrollo Sostenible con los Objetivos de Desarrollo Sostenible, también se refiere al consumo sostenible, en el Objetivo 12. ("Garantizar modalidades de consumo y producción sostenibles") reafirma la

${ }^{19}$ Para más información sobre el Programa, ver PROGRAMA DE NACIONES UNIDAS PARA EL MEDIO AMBIENTE. UNEP. 2015. Estrategia Regional de Consumo y Producción Sostenibles (CPS) para la implementación del Marco Decenal de CPS (10YFP) en América Latina y el Caribe (2015-2022) UNEP aplicación del Marco Decenal de Programas sobre Modalidades de Consumo y Producción Sostenibles, con la participación de todos los países y bajo el liderazgo de los desarrollados, teniendo en cuenta el grado de desarrollo y las capacidades de los países en desarrollo. Fija como meta para el 2030 lograr la gestión sostenible y el uso eficiente de los recursos naturales, reducir a la mitad el desperdicio mundial de alimentos per cápita en la venta al por menor y a nivel de los consumidores, disminuir de manera sustancial la generación de desechos mediante políticas de prevención, reducción, reciclaje y reutilización y velar para que las personas de todo el mundo tengan información y conocimientos pertinentes para el desarrollo sostenible y los estilos de vida en armonía con la naturaleza. Y para el 2020, lograr la gestión ecológicamente racional de los productos químicos y de todos los desechos a lo largo de su ciclo de vida, de conformidad con los marcos internacionales convenidos, y reducir de manera significativa su liberación a la atmósfera, el agua y el suelo.

El objetivo del consumo y la producción sostenibles es hacer más y mejores cosas con menos recursos, incrementando las ganancias netas de bienestar de las actividades económicas mediante la reducción de la utilización de los recursos, la degradación y la contaminación durante todo el ciclo de vida, logrando al mismo tiempo una mejor calidad de vida. En ese proceso participan distintos interesados, entre ellos empresas, consumidores, encargados de la formulación de políticas, investigadores, científicos, minoristas, medios de comunicación y organismos de cooperación para el desarrollo. También es necesario adoptar un enfoque sistémico y lograr la cooperación entre los participantes de la cadena de suministro, desde el productor hasta el consumidor final. Consiste en involucrar a los consumidores mediante la sensibilización y la educación sobre el consumo y los modos de vida sostenibles, facilitándoles información adecuada a través de normas y etiquetas, y participando en la contratación pública sostenible, entre otros. Se han identificado los siguientes programas iniciales: información al consumidor, educación y estilos de vida sustentables, compras públicas sustentables, construcciones sustentables y turismo sustentable y ecoturismo. ${ }^{20}$

El Convenio Marco sobre Cambio Climático - El Acuerdo de París 2015, también considera que la adopción de estilos de vida y pautas de consumo y producción sostenibles, por parte de los países desarrollados, es una contribución

${ }^{20}$ Toda esta información se encuentra disponible en ONU. 2015. Proyecto de documento final de la cumbre de las Naciones Unidas para la aprobación de la agenda para el desarrollo después de 2015. Anexo Transformar nuestro mundo: la Agenda 2030 para el Desarrollo Sostenible (U.N. Doc. A/69/L.85, 12 de agosto de 2015) 
importante a los esfuerzos por hacer frente al cambio climático.

En ese contexto, se pone en relieve la importancia de la transferencia de tecnología a los países en desarrollo, así como las disposiciones en materia de financiación, acceso a la información y derechos de propiedad intelectual acordadas en el Plan de Aplicación de las Decisiones de Johannesburgo y en especial, el acceso a las tecnologías ambientalmente racionales, desarrollo, transferencia, difusión, nuevos conocimientos y conocimientos técnicos y especializados, en particular a los países en desarrollo y con economías en transición. El apoyo de la comunidad internacional puede contribuir a que esos países desplieguen sus propias soluciones innovadoras, investigaciones científicas y nuevas tecnologías ambientalmente racionales. Además, destaca que el uso de tecnologías menos contaminantes y de alto rendimiento energético es un elemento importante para el desarrollo sostenible, incluso para hacer frente al cambio climático.

Conforme lo señala la Organización Mundial del Comercio (OMC) en la Comunicación de Ecuador 2013, y como una contribución del sistema multilateral del comercio a las estrategias globales para ampliar el acceso a las energías limpias, incrementar la eficiencia energética y acelerar su establecimiento a nivel mundial, dicho organismo se propone evaluar la eliminación o reducción de las restricciones o barreras existentes y la facilitación del acceso y uso a las tecnologías ambientalmente sanas (TAS). De igual manera, admite que es necesario una verdadera y real cooperación internacional entre los países desarrollados y el sector privado que se manifieste en intercambios justos y equilibrados, en la creación de pautas justas y razonables para el uso, intercambio, creación y difusión de las TAS en cuanto al esperado éxito de la revolución de la economía verde en los países en desarrollo vulnerables y los menos avanzados, para lo cual una reorientación del régimen de propiedad intelectual mundial es vital en la lucha para la adaptación y/o la mitigación de los efectos nocivos del cambio climático.

Para el caso de las TAS estiman que es necesario considerarlas como un "bien público" debido a que por su naturaleza y finalidad tienen el objetivo de promover el bienestar social global a través de la adaptación y/o mitigación de los efectos del cambio climático, que se traduce en la adopción de políticas públicas gubernamentales tendientes a la promoción de la salud pública y ambiental.

El Objetivo 9 de los Objetivos de Desarrollo Sostenible ("Construir infraestructuras resilientes, promover la industrialización inclusiva y sostenible y fomentar la innovación") propone aumentar la investigación científica y mejorar la capacidad tecnológica de los sectores industriales de todos los países, en particular los países en desarrollo, entre otras cosas fomentando la innovación y aumentando el número de trabajadores en el campo de la investigación y el desarrollo así como incrementando los gastos en investigación y desarrollo de los sectores público y privado. El Objetivo 10 ("Reducir la desigualdad en y entre los países ") plantea la necesidad de aplicar el principio del trato especial y diferenciado para los países en desarrollo, en particular los países menos adelantados, de conformidad con los acuerdos de la Organización Mundial del Comercio.

Finalmente, el Objetivo 17 ("Fortalecer los medios de ejecución y revitalizar la Alianza Mundial para el Desarrollo Sostenible")bajo el título "Tecnología" considera fundamental promover el desarrollo de tecnologías ecológicamente racionales y su transferencia, divulgación y difusión a los países en desarrollo en condiciones favorables, poner en pleno funcionamiento, a más tardar en 2017, el banco de tecnología y el mecanismo de apoyo a la ciencia, la tecnología y la innovación para los países menos adelantados y aumentar la utilización de tecnología instrumental, en particular de la tecnología de la información y las comunicaciones.

Para el cumplimiento de este objetivo, las Partes ponen en funcionamiento el Mecanismo de Facilitación de la Tecnología que se estableció en la Agenda de Acción de Addis Abeba con el fin de apoyar el logro de los Objetivos de Desarrollo Sostenible. El mismo se basará en un marco de colaboración múltiple entre los Estados Miembros, la sociedad civil, el sector privado, la comunidad científica, las entidades de las Naciones Unidas y otras partes interesadas, y estará integrado por un equipo de tareas interinstitucional de las Naciones Unidas sobre la ciencia, la tecnología y la innovación en pro de los Objetivos de Desarrollo Sostenible, un foro de colaboración entre múltiples interesados sobre la ciencia, la tecnología y la innovación a favor de los Objetivos de Desarrollo Sostenible, y una plataforma en línea.

Recientemente, el Acuerdo de París, en el artículo nueve, obliga a las Partes que son países desarrollados a proporcionar recursos financieros a las que son países en desarrollo para prestarles asistencia tanto en la mitigación como en la adaptación, teniendo en cuenta el importante papel de los fondos públicos, a través de diversas medidas, como el apoyo a las estrategias controladas por los países, basándose en las necesidades y prioridades de las que son países en desarrollo. En el artículo diez expresamente se reconoce la importancia de hacer plenamente efectivos el 
desarrollo y la transferencia de tecnología para mejorar la resiliencia al cambio climático y reducir las emisiones de gases de efecto invernadero. A fin de impulsar los enfoques colaborativos en la labor de investigación y desarrollo y de facilitar el acceso de las Partes que son países en desarrollo a la tecnología, en particular en las primeras etapas del ciclo tecnológico, pone al servicio del Acuerdo el Mecanismo Tecnológico (creado en el marco de la Convención) y, con medios financieros, el Mecanismo Financiero de la Convención.

\section{Economía circular. Análisis del ciclo de vida del producto.} Cradle to cradle

La esencia de la economía circular reside en diseñar productos sin desechos, productos que faciliten su desmontaje y su reutilización, así como en definir modelos empresariales para que los fabricantes puedan ser incentivados económicamente para recoger, volver a fabricar y distribuir los productos que hacen. Se basa en el Análisis del Ciclo de Vida (ACV) el cual es una metodología que intenta identificar, cuantificar y caracterizar los diferentes impactos ambientales potenciales, asociados a cada una de las etapas del ciclo de vida de un producto.

La herramienta del Análisis del Ciclo de Vida fue desarrollada en los años sesenta y utilizada para la prevención de la polución desde los setenta. Podemos decir que no existen procedimientos específicos o guías a seguir, pero sí una serie de aproximaciones que pueden ser útiles en función de las necesidades a resolver por medio de esta metodología.

El principio básico de la herramienta es la identificación y descripción de todas las etapas del ciclo de vida de los productos, desde la extracción y retratamiento de las materias primas, la producción, la distribución y uso del producto final hasta su posible reutilización y reciclaje del producto. La vida de un producto empieza en el diseño y desarrollo, siguiendo por la adquisición de materias primassu extracción-, continúa con el proceso y fabricación, es decir todas las actividades para convertir las materias primas y energía en el producto deseado, distribución y transporte del producto final al cliente y finaliza con las actividades de reutilización y reciclaje, si ello fuese posible, o con la gestión de los residuos, es decir, una vez que el producto ha servido a su función y se devuelve al ambiente como residuo.

El Análisis del Ciclo de Vida es la base del ecodiseño, el ecoetiquetado y las Declaraciones Ambientales de Producto. La norma ISO 14040 - Gestión ambiental. Análisis de ciclo de vida. Principios y marco de referencia- ayudó a determinar la estructura de trabajo y uniformar sus métodos, procedimientos y criterios. Esta metodología funciona como una herramienta de gestión ambiental, por medio de la cual los productores pueden predecir y comparar los impactos ambientales de un producto "desde que nace hasta que muere". Esto último significa que los productos tienen un solo uso. Popularmente, conocemos este planteamiento como cradle to grave -de la cuna a la tumba.

Ante esta circunstancia, en la década de los noventa, el arquitecto estadounidense Bill McDonough y el químico alemán Michael Braungart desarrollaron el concepto cradle to cradle- de la cuna a la cuna- y su proceso de certificación, basado en la idea de que todas las materias primas de un producto se pueden separar al final de su ciclo de vida y reutilizarse para producir nuevos materiales de la misma calidad que los originales. Esto se logra a través del upcycling o "supra-reciclaje" que consiste en transformar un objeto sin uso o destinado a ser un residuo en otro de igual o mayor utilidad y valor. ${ }^{21}$

Recientemente, la Unión Europea propuso un nuevo Reglamento modificatorio del actual Reglamento 2003/2003 sobre abonos. La pretensión del proyecto de Reglamento, presentado en marzo de 2016, consiste en transformar una gran parte de los residuos orgánicos en recursos, vale decir la conversión de biorresiduos en materias primas que puedan utilizarse para fabricar fertilizantes, convirtiéndolos en materias primas secundarias. ${ }^{22}$

\section{Ecoetiquetado}

El etiquetado ecológico son marcas o sellos que suministran información sobre bienes y servicios que poseen un comportamiento ambiental respetuoso y estimulan su comercialización. Si bien todo producto genera cierta presión sobre el ambiente, su presencia indica que el impacto ambiental ha sido reducido respecto a otros similares existentes en el mercado.

Según la definición de la Asociación Española para la Calidad, una etiqueta ecológica es un "mecanismo voluntario de valoración y calificación ambiental, que de forma oficial,

\footnotetext{
${ }^{21}$ Sobre el proceso de reutilización, consultar EL ANÁLISIS DEL CICLO DE VIDA. (editorial). 2013. Ecointeligencia. 4 de febrero de 2013. (Fecha de acceso 13 de marzo de 2016) URL disponible en: http://www.ecointeligencia.com/2013/02/analisis-ciclo-vida-acv/

${ }^{22}$ El Reglamento se puede obtener en COMISIÓN EUROPEA. 2016. Economía circular: nuevo reglamento para impulsar la utilización de abonos orgánicos y obtenidos de los residuos. Comunicado de prensa, 17 de marzo de 2016. Bruselas: Press releases database. (Fecha de acceso 20 de abril de 2016) URL disponible en: http://europa.eu/rapid/pressrelease_IP-16-827_es.htm
} 
certifica que un producto es considerado como más eficiente ambientalmente que el resto" (AEC 2013).

Tiene por finalidad advertir al consumidor sobre la duración de vida o el número estimado de utilizaciones de los productos, para que pueda escoger y elegir el que sea más conveniente en el momento de su adquisición, y sobre todo con pleno conocimiento de causa.

En este sentido, se hace necesario contar con un etiquetado en el que figure el precio por año estimado, en función de la vida útil del producto, a los efectos de fomentar la adquisición de aquellos que sean más sostenibles, conforme la duración de vida que se anuncie. De esta forma, se propicia que el consumidor pueda, por ejemplo, adquirir productos más caros en el momento de la compra, pero también más rentables al ser más amortizables en el tiempo.

El ecoetiquetado se erige como otra de las alternativas contra las prácticas empresariales de la obsolescencia programada, en la medida en que el consumidor tenga la posibilidad de elegir marcas que no usan estas técnicas y que, por ende, sus productos duren más. Marcas que informen abiertamente en sus etiquetas sobre dichas circunstancias, y que no sustraigan dichos parámetros al conocimiento del consumidor.

Desde otro ángulo, no desconocemos que la útil herramienta del etiquetado ecológico puede devenir en una pauta de discriminación arbitraria o injustificada respecto de las exportaciones de productos de países en vías de desarrollo, produciendo, en definitiva, cierta restricción encubierta en el comercio internacional. La difusión que están alcanzado los sistemas de ecoetiquetado en los países desarrollados, en contraposición con los escasos avances registrados en los países en desarrollo, tiene un potencial efecto distorsionador sobre el comercio internacional, por utilizarse como barreras no arancelarias.

La Organización Mundial de Comercio (OMC) sostiene que, para evitar que los sistemas de etiquetado ecológico se conviertan en obstáculos técnicos al comercio (OTC), éstos deben ser de carácter voluntario y seguir los principios de la nación más favorecida y trato nacional. De esta forma, no serían los gobiernos quienes definen las prácticas que son preferibles, sino los consumidores al elegir qué producto comprar con base a la información proporcionada por éstas.

En 1994 fue fundada la Red Mundial de Etiquetado Ecológico, The Global Ecolabelling Network -GEN, por sus siglas en inglés-, como una asociación sin fines de lucro, con el objetivo de desarrollar, mejorar y promover el ecoetiquetado de productos y servicios a nivel mundial.
En la actualidad, Brasil es el único país Latinoamericano miembro de dicha red mundial. El Rótulo Ambiental llamado MarcaABNT -Qualidade Ambiental, fue ideado en el año 1993 por la Asociación Brasileña de Normas Técnicas (ABNT), tomando como base la iniciativa de "La Flor" de la Unión Europea, y re-lanzado en 2008, logrando la primera certificación en junio de 2011. Es un esquema voluntario, de certificación por tercera parte que procura la mejora continua de los procesos de la organización certificada hacia la excelencia ambiental. Así, las metas que se pretenden alcanzar con la certificación son la reducción del consumo de energía, agua y materiales y la minimización de la contaminación generada por la producción, el uso y la disposición final de los productos y servicios. El sello brasileño es uno de los sistemas de eco-etiquetado sudamericanos más desarrollados y completos (Gillet 2014).

Entre los eco sellos podemos mencionar Ángel Azul Alemania, Cisne Blanco - Suecia, Noruega, Finlandia e Islandia, Green Seal - Estados Unidos, Enviromental Choice - Canadá, Eco- Mark - Japón, Eco- Mark - India, Green Mark - Taiwan, Korea Environmental Labelling Association - Corea.

Finalmente, la Fundación Feniss, Fundación Energía e Innovación Sostenible sin obsolescencia programada erigida por un grupo de empresarios e inventores preocupados por la sostenibilidad de la industria, creó el sello "ISSOP" (Innovación Sostenible Sin Obsolescencia Programada) que podrán incorporar las empresas en sus artículos siempre que cumplan determinados requisitos tales como que los productos sean reparables por un coste menor al de comprar uno nuevo o que la garantía del producto sea superior al período obligatorio por ley.

También se crearán centros de reparaciones de productos y se desarrollará una aplicación mediante la cual el consumidor podrá escanear el código de barras de los productos y conocer su lugar de fabricación, su vida útil, o el coste de reparación aproximado en caso de avería. Lo novedoso de este sello es que se otorga además de manera gratuita (González de Uriarte 2016).

\section{Reciclaje de equipos}

La mayoría de los equipos informáticos tienen un tiempo de vida útil relativamente corto, la cantidad de componentes tóxicos que se generan cuando terminan en vertederos, son una fuente directa de contaminación de la tierra y el agua. En cuanto a la normativa vigente, a nivel internacional, se debe hacer referencia al Convenio de Basilea sobre el 
Control de los Movimientos Transfronterizos de los Desechos Peligrosos y su Eliminación de 1989 y a la Directiva Europea 2002/96/CE que es una de las primeras normas especiales sobre el tratamiento de los residuos de los aparatos eléctricos y electrónicos. Conforme al artículo tres de la Directiva Europea 2002/96/CE, el reciclaje es: "el reprocesado de los materiales de los residuos, dentro de un proceso de producción, para su finalidad inicial o para otros fines"

En especial, la nueva Directiva Europea sobre Residuos de Aparatos Eléctricos y Electrónicos, Directiva Europea 2012/19/UE, en su artículo cuatro hace mención a la manera en que debe diseñarse un producto, indicando que los Estados miembros adoptarán las medidas adecuadas para que se apliquen los requisitos de diseño ecológico que facilitan la reutilización y el tratamiento de los RAEE y los productores no impidan mediante características de diseño específicas o procesos de fabricación específicos la reutilización de los RAEE, salvo que dichas características de diseño específicas o dichos procesos de fabricación específicos presenten grandes ventajas, por ejemplo, respecto a la protección del medio ambiente.

La aplicación de la responsabilidad extendida del productor exige que el productor respete las normas de calidad y asuma la responsabilidad por el impacto del producto al terminar su ciclo de vida útil. Sin embargo, en Latinoamérica existen circunstancias que obstaculizan la vigencia de este régimen y la figura del productor es más bien borrosa e imprecisa.

En Argentina, el proyecto de Ley de Gestión de Residuos de Aparatos Eléctricos y Electrónicos contó con media sanción del Senado (4 de mayo de 2011), pero fue demorado en la Cámara de Diputados.Este proyecto establecía un sistema de gestión de los residuos electrónicos en todo el país, la separación de la basura domiciliaria por su potencial contaminante y el reciclaje de los componentes de valor para su reingreso al mercado. Además, les exigía a los fabricantes una responsabilidad extendida por lo que deberían hacerse cargo legal y financieramente de la gestión y tratamiento de sus propios residuos, y al Estado la provisión de una infraestructura nacional para transporte, acopio recuperación y reciclado. El 12 de julio de 2012 se presentó el mismo proyecto, pero perdió estado parlamentario y se volvió a presentar, el 18 de septiembre de 2013 ante la Cámara de Senadores, sin lograr sanción. En la Provincia de Buenos Aires, desde 2011, está vigente la Ley No 14321, que regula la gestión sustentable de Residuos de Aparatos Eléctricos y Electrónicos, conforme lo preceptuado en el artículo 41 de la Constitución Nacional y el artículo 28 de la Constitución Provincial; guardando concordancia con lo establecido por el Convenio de Basilea. En la Ciudad
Autónoma de Buenos Aires, en 2008, se dictó la Ley N 2807 que establece medidas para la Gestión de Aparatos Electrónicos en Desuso del Poder Ejecutivo de la Ciudad, de aplicación exclusiva al ámbito del sector administrativo público en forma incompleta (Porcelli 2014).

En Argentina, existe una amplia red de empresas que se dedican a la recepción y al tratamiento del e-wasted, entre ellas mencionamos:

a) Escrap: es una red de operadores del mercado de residuos y subproductos que favorece el encuentro entre quienes necesiten desprenderse de dispositivos electrónicos obsoletos, y aquellas personas, empresas, gobiernos $\mathrm{u}$ organizaciones no gubernamentales que pueden valorizar el residuo mediante su reuso, reciclado o recupero de materias primas.

b) Red Reciclar. Ecovalor: integrada por empresas dedicadas al reuso de aparatos eléctricos, electrónicos y electrodomésticos. Su objetivo es llegar con niveles de calidad y garantía a sectores de la sociedad que no tienen acceso al mercado. También a empresas operadoras que reciben y certifican la disposición final de aquellas partes y componentes que no pueden reusarse, cerrando el ciclo limpio del reciclado con reuso.

c) Cooperativa La toma del Sur: constituida por un grupo de trabajadores que han quedado desocupados, dicha cooperativa se dedicó desde un inicio al reciclado de botellas, cartones y todo tipo de papel. Ya desde 2007, la cooperativa se inició en la recuperación de elementos electrónicos. Hoy, ofrece un servicio de recepción y recolección de materiales post-consumo y rezagos varios (electrónicos, plásticos, vidrios, papel, madrea, metales, hierro, entre otros).

d) Industrias Dalafer: esta empresa retira materiales scrap (del inglés desecho o residuo) en todo el país, asegurando a sus clientes y proveedores el tratamiento de los mismos, extendiendo certificado de disposición final.

\section{CONCLUSIÓN}

El desafío de hoy es, sin duda, producir cambios en los patrones de consumo y producción: un cambio de paradigma en el consumo. Toda pretensión de cuidar y mejorar el 
mundo supone cambios profundos en los estilos de vida, los modelos de producción y de consumo.

Frente a la situación del progresivo deterioro ambiental, ya no es suficiente con reducir el impacto ambiental en el producto terminado, es decir, en el final de la cadena de producción, sino que es necesario un cambio en los modelos y sistemas de producción, comenzando desde la extracción hasta el reciclaje y la posterior gestión de residuos, centrando en una economía circular y la metodología cradle to cradle, y propender a la separación de las materias primas al final del ciclo de vida del producto no consumible y reutilizarse para producir nuevos materiales de la misma calidad que los originales.

Recordamos los compromisos asumidos en la Declaración de Río, el Programa 21 y el Plan de Aplicación de las Decisiones de Johannesburgo relativos a la producción y consumo sostenibles y conforme las Directrices de las Naciones Unidas sobre la Protección al Consumidor, la responsabilidad del consumo sostenible la comparten todos los miembros de la sociedad, a saber, los consumidores informados, los gobiernos, las empresas, los sindicatos y las organizaciones ambientalistas y de consumidores. Es necesario cambiar la manera en que las sociedades consumen y producen para lograr el desarrollo sostenible mundial.

La conciencia de la gravedad de la crisis cultural y ecológica necesita traducirse en nuevos hábitos, lo que constituye un gran desafío cultural, espiritual y educativo. Un cambio en los estilos de vida podría llegar a ejercer una sana presión sobre los que tienen poder político, económico y social.

En consecuencia, no es posible hablar de un consumo sustentable y una defensa del ambiente, si no pensamos en un sistema económico social y jurídico sustentable, para lo cual consideramos fundamental la toma de decisiones tanto en lo económico como en lo jurídico.

En primer lugar, educar al consumidor para la autorregulación, como un ser humano satisfecho en sus necesidades y calidad de vida, no en cuanto a la cantidad sino en cuanto a la calidad de bienes y servicios.

Así, debería surgir un nuevo tipo de consumidor, que atienda a patrones de conducta amigables con el ambiente, consumidores informados sobre productos, hábitos y acciones que cuidan el ambiente. De esta manera, los consumidores se vuelven más independientes y con mayor capacidad para tomar decisiones dentro del mercado. Es una elección más compleja que comprar "verde", se trata de plantear una nueva forma de consumir, con información y con prácticas ambientales incorporadas en otros ámbitos.

Todo ello se debe complementar con la modificación de la legislación que obligue a las empresas al establecimiento de un ecoetiquetado o eco sellado, similar a la que rige en Brasil, que informe al consumidor la vida útil de los productos no consumibles conforme parámetros técnicos verificables. De esta manera, el consumidor puede optar por precio más barato y menos duración del producto o pagar más, pero con mayor durabilidad y, en consecuencia, más rentables al ser más amortizables en el tiempo.

Además, que extienda la garantía legal de los productos a plazos bastante más largos que los que hoy prevé la ley a los fines de comenzar a modificar las conductas empresarias al respecto, forzando, a partir del plazo más extenso de responsabilidad del proveedor, al mayor cuidado en la elaboración de los productos, y simultáneamente pautar con amplitud prudente la obligatoriedad de la garantía de servicio técnico adecuado y suministro departes y repuestos.

También consideramos importante penalizar expresamente la obsolescencia programada en todas sus manifestaciones, siguiendo el modelo de Francia y que se sancione la tan postergada Ley de Gestión de Residuos de Aparatos Eléctricos y Electrónicos a nivel nacional, que acentúe la rigurosidad en las instrucciones de uso sobre reciclado y reutilización de partes, a cargo del proveedor, que deberá ser obligatoria en productos que contengan elementos ambientalmente nocivos o sean fabricados con componentes desechables de nula o lenta degradación, y exigir a los fabricantes una responsabilidad extendida por lo que deberían hacerse cargo legal y financieramente de la gestión y tratamiento de sus propios residuos, acopio, recuperación y reciclado.

Finalmente, el Mensajero de la Paz de la ONU, el actor estadounidense Leonardo DiCaprio, en su discurso durante la ceremonia de firma del Acuerdo de París, desafío a los líderes mundiales con estas palabras:

"Ahora piensen en la vergüenza que cada uno de ustedes llevará consigo cuando nuestros hijos y nietos miren hacia atrás y se den cuenta que tuvimos una oportunidad para detener esta devastación, pero que simplemente faltó la voluntad política para hacerlo»(ONU 2016).

\section{REFERENCIAS}

\subsection{ALTERNATIVAS A LA OBSOLESCENCIA} PROGRAMADA. (editorial) 2014. Revista Diseño Social. 6 de febrero de 2014. (Fecha de acceso 10 de octubre de 2016). URL disponible en: 


\section{Consumo (In) sostenible. Desafíos ambientales}

http://disenosocial.org/obsolescencia-0512/.

AGUILAR-BENÍTEZ, O. 2011. El Proceso de Globalización y la Actual Crisis Financiera Capitalista. Documentos de Trabajo $\mathrm{N}^{\circ}$ 67. CEID, Buenos Aires.20pp.

ARIAS-CÁU, E. \& BAROCELLI, S. 2013. El sobreendeudamiento del consumidor y la adicción al consumo MicrojurisMJ-DOC-6461-AR | MJD6461

ASOCIACIÓN ESPAÑOLA PARA LA CALIDAD. AEC. 2013. Etiquetas Ecológicas: más que una herramienta de marketing. Centro de Información para la Calidad. (Fecha de acceso 10 de agosto de 2016) URL disponible en:

http://www.aec.es/c/document_library/get_file?uuid $=$ f5c52708-5b3e-4b94-80d1-

97d9a1c416cb\&groupId=10128

AVELLANEDA, S. 2011. Argentina Sustentable. RevistaAgua y Medio Ambiente: 30-38

BAUMAN, Z. 2007. Vida de consumo. Fondo de Cultura Económica, México D.F. 205pp.

BIDART-CAMPOS, G. 1998. Manual de la Constitución Reformada Tomo I. Ediar, Buenos Aires. 451pp.

BURGOS, V. 2016. Coltán, el mineral para la fabricación de componentes electrónicos. Mundo Digital. (Fecha de acceso el 28 de octubre de 2016) URL disponible en: http:// www.mundodigital.net/coltan-o-coltan-elmineral-de-componentes-electronicos/

CAFFERATTA, N. 2014. Derecho ambiental en el Código Civil y Comercial de la Nación. (Nov) La Ley, Suplemento Especial Nuevo Código Civil y Comercial 17 de noviembre de 2014

CAMPBELL, C. 2005. I shop therefore I know that I am: the metaphysical basis of modern consumerism. En EKSTROM, K.M. \& BREMBECK, H. (eds.) Elusive Consumption: 10-22. Nueva York

CAMUS, A. 1994. La misión del escritor. En GRINBERG, M. (ed.). Visionarios Implacables:20-23. Mutantia, Buenos Aires.

CHACÓN-TAPIAS, F. 2014. La Travesía Obsoleta. La indefensión del consumidor. Tesis de Grado Facultad de Jurisprudencia. Bogotá D.C.
CHIOU, P. 2011. Los minerales de tierras raras: imprescindibles para la tecnología. México CNN. 3 de septiembre de 2011. (Fecha de acceso el 11de mayo de 2016) URL disponible en: http:/ / mexico.cnn.com/tecnologia/2011/09/03/losminerales-de-tierras-raras-imprescindibles-para-latecnologia

COBRE. SALUD, MEDIO AMBIENTE Y NUEVAS TECNOLOGÍAS. (editorial) Copper Connects Life. (Fecha de acceso 30 de septiembre de 2016). 128pp. URL disponible en: http://www.ecosea.cl/pdfs/Cobre_Salud_Medio_Amb iente_Nuevas_Tecnologias.pdf

COMISIÓN EUROPEA. 2016. Economía circular: nuevo reglamento para impulsar la utilización de abonos orgánicos y obtenidos de los residuos. Comunicado de prensa, 17 de marzo de 2016. Bruselas: Press releases database. (Fecha de acceso 20 de abril de 2016) URL disponible en: http://europa.eu/rapid/pressrelease_IP-16-827_es.htm

COMITÉ DE DERECHOS ECONÓMICOS, SOCIALES Y CULTURALES. 2002. Cuestiones Sustantivas que se Plantean en la Aplicación del Pacto Internacional de Derechos Económicos, Sociales y Culturales. Observación General No 15. El Derecho al Agua Artículos 11 y 12 del Pacto Internacional de Derechos Económicos, Sociales y Culturales.Naciones Unidas (NU), Consejo Económico y Social E/C.12/2002/11, Ginebra. 19pp. p.2

CRETTAZ, J. 2016. El Gobierno lanzó el plan de celulares $4 \mathrm{G}$ en cuotas y anunció inversiones por $\$$ 76.500 millones. Diario La Nación. 19 de Julio de 2016. Sección Tecnología. (Fecha de acceso 1 de agosto de 2016) URL disponible en: http://www.lanacion.com.ar/1919773-el-gobiernolanzo-el-plan-de-celulares-4g-en-cuotas-y-anuncioinversiones-por-76500-millones

DELGADO, A. 2015. Ecuador propone ley contra la obsolescencia programada. FayerWayer Sección Política. 2 de marzo de 2015. (Fecha de acceso el 15 de marzo de 2016) URL disponible en. https://www.fayerwayer.com/2015/03/ecuadorpropone-ley-contra-la-obsolescencia-programada/

EL ANÁLISIS DEL CICLO DE VIDA. (editorial). 2013.Ecointeligencia. 4 de febrero de 2013. (Fecha de acceso 13 de marzo de 2016) URL disponible en: 
Ambiente y Sostenibilidad 2016 (6): 105-135

Revista del Doctorado Interinstitucional en Ciencias Ambientales

http://www.ecointeligencia.com/2013/02/analisisciclo-vida-acv/

ESPINOSA, A. Usar y Tirar. Obsolescencia programada. 2014. Revista Placet. 8 de mayo de 2014. Madrid (Fecha de acceso 10 de agosto de 2016) URL disponible en: http:/ / revistaplacet.es/obsolescencia-programada

FAVOREAU, L. 1990 El bloque de constitucionalidad.Civitas, Madrid.

FRANCIA PLANTA CARA A LA OBSOLESCENCIA PROGRAMADA CON PENAS DE CÁRCEL Y MULTAS DE 300.000 EUROS. (editorial) 2014. El Economista.19 de octubre de 2014 (Fecha de acceso el 14 de marzo de 2016) URL Disponible en: http://www.eleconomista.es/internacional/noticias/61 71070/10/14/Francia-planta-cara-a-la-obsolescenciaprogramada-con-penas-de-carcel-y-multas-de-300000euros.html

FRANCISCO. 2015.Carta Encíclica Laudato Si, 24de mayo de 2015. (Fecha de acceso 20 de septiembre de 2016).192pp. p.88 URL disponibleen: http://w2.vatican.va/content/francesco/es/encyclicals /documents/papa-francesco_20150524_enciclicalaudato-si.html

FUNDACIÓN FORUM AMBIENTAL. Guía para la Ecoeficiencia. (Fecha de acceso 25 de noviembre de 2014) URL disponible en:http://www.forumambiental.org/pdf/guiacast.pdf

FUNDACIÓN VIDA SILVESTRE. 2015. Plataforma para la Agenda Pública Argentina 2016-2020 - Cinco ideas para una Argentina Sustentable. Política de Sustentabilidad para una Nación Competitiva y Soberana. WWF, Buenos Aires. 16p.

GILLET, S. 2014. Eco-etiquetado en el MERCOSUR Potencialidades del Enfoque Regional en la Adopción de Modalidades de Producción y Consumo Sustentables Tesis de Maestría. Facultad de Ciencias Económicas. Universidad de Buenos Aires, Argentina.

GONZÁlEZ DE URIARTE, N. 2016. Un sello distinguirá a empresas por fabricar productos sin obsolescencia programada. El Diario,20 de noviembre de 2015. (Fecha de acceso 15 de marzo de 2016) URL disponible en: http://www.eldiario.es/norte/euskadi/obsolescenciaprogramada-sello-certificacion-empresaspartidos_0_454254701.html
ISSN: 2339-3122

Digital

GOÑI, R. La Obsolescencia Programada y el Consumo Responsable. Eldiario.es, 3 de abril de 2015. (Fecha de acceso 20 de octubre de 2016) URL disponible en: http://www.eldiario.es/zonacritica/obsolescenciaprogramada-consumo-responsable_6_372772738.html

GREENPEACE. 2010. Componentes Tóxicos. (Fecha de acceso 11 de octubre de 2016) URL disponible en: http://www.greenpeace.org/argentina/es/campanas/ contaminacion/basura-electronica/ComponentesToxicos/

GREENPEACE. 2012. Minería y Basura Electrónica. El manejo irracional de los recursos. Greenpeace, Argentina. 25pp.

HERRERA, M. et al. 2015a. Código Civil y Comercial de la Nación Comentado Título Preliminar y Libro Primero Infojus, Buenos Aires. 631pp.

HERRERA, M. et al. 2015b. Código Civil y Comercial de la Nación Comentado Tomo III Libro Tercero. Artículos 724 a 1250 Comentarios a los arts. 1092 a 1122 elaborados por Rubén Stiglitz. Infojus, Buenos Aires. 641pp.

KENNEDY, J. 1962. The White House "Special message to Congress on protecting consumer interest, 15 March 1962" 15 de marzo de 1962J.F. Kennedy Presidential Library and Museum. Collection:Papers of John F. Kennedy. Presidential Papers. President's Office Files. [Fecha de acceso 21 de agosto de 2016]URL disponible en https://www.jfklibrary.org/Asset-

Viewer/Archives/JFKPOF-037-028.aspx

LEONARD, A. 2010. La historia de las cosas. Fondo de Cultura Económica, Argentina. 385pp.

LORENZETTI, R. 1998. Reglas de solución de conflictos entre propiedad y medio ambiente. La Ley 1998 (A): 1024-1032, sec. doctrina.

LORENZETTI, R. (dir.) DE LORENZO, M.\& LORENZETTI, P. (cords.) 2015. Código Civil y Comercial de la Nación Comentado. Tomo VI. Arts. 1021 a 1279. Rubinzal-Culzoni, Buenos Aires. 901pp.

MARTÍN-PEÑA, R. 2014. Consumidores y técnicas de reciclaje pueden reducir la nociva basura electrónica. Revista Electrónica de Ciencia, Tecnología, Sociedad y Cultura. 4 de julio de 2014. (Fecha de acceso 27 de junio de 2016) URL disponible en: 


\section{Consumo (In) sostenible. Desafíos ambientales}

http://www.tendencias21.net/Consumidores-ytecnicas-de-reciclaje-pueden-reducir-la-nociva-basuraelectronica_a35269.html

MARTÍNEZ, A. \& PORCELLI, A. 2015. Implicancias de las Tecnologías Informáticas en el Ambiente y Nuevas Tendencias en el Desarrollo de la Informática Verde como aporte al Desarrollo Sustentable. Revista Actualidad Jurídica Ambiental.Recopilatorio Mensual (50):8-36

MÁS DE 60.000 CELULARES VENDIDOS EN 10 DÍAS CON EL PLAN DE CUOTAS DEL GOBIERNO. (editorial). 2016. Diario La Nación. 1 de agosto 2016.Sección Tecnología. (Fecha de acceso 1 de agosto de 2016) URL disponible en: http:/ / www.lanacion.com.ar/1923704-mas-de-60000celulares-vendidos-en-10-dias-con-el-plan-de-cuotasdel-gobierno.

MEDINA, G. \& RIVERA, C. (dirs.) ESPER, M. (cord.) 2014. Código Civil y Comercial de la Nación Comentado. Tomo III. Artículos 724 a 1250.La Ley, Buenos Aires. 1091pp.

MERCOSUR. Política de Promoción y Cooperación en Producción y Consumo Sostenibles en el MERCOSUR. 2007. MERCOSUR/LXVIII CMC/P.DEC. N $\mathrm{N}^{\mathrm{o}}$ 26/07 Anexo Artículo 1 b) y c) 28 de junio de 2007, Asunción. (Fecha de acceso 9 de septiembre de 2016) URL disponible en: http://www.ambiente.gov.ar/archivos/web/MERCOSUR/File/ SGT\%206\%20Ordinaria\%20XL/Anexo-IV-RO-XLPoliticaProduccion-Cons-ROXL.pdf

MONTEVERDE, F. 2010.E-waste y su incorporación en la agenda gubernamental e internacional. En: UNESCO (ed.) Plataforma Regional de Residuos electrónicos para América Latina RELAC. Los residuos electrónicos: Un desafío para la Sociedad del Conocimiento en América Latina y el Caribe: 213-225. UNESCO RELAC, Montevideo.

OBSOLESCENCIA PROGRAMADA (editorial)La Opinión Edición digital del 30 de enero de 2016. (Fecha de acceso 10 de marzo de 2016. URL disponible en: http://diariolaopinion.com.ar/noticia/83701/obsolesce ncia-programada

OBSOLESCENCIA PROGRAMADA: TIPOS Y FORMAS (editorial) 2014. Eco inteligencia, 10 de junio de 2014. (Fecha de acceso 15 de octubre de 2016). URL disponible http://www.ecointeligencia.com/2014/06/obsolescenc ia-programada-tipos-formas/\#lightbox/1/

OCU. 2011. Impresoras ¿con truco?17 de marzo de 2011. Sección Tecnología. Fecha de acceso 25 de septiembre de 2016). URL disponible en: http://www.ocu.org/tecnologia/nc/noticias/impresor as-con-truco-536284

OMC. 2013. Contribución de la Propiedad Intelectual a la facilitación de la transferencia de tecnologías ecológicamente racionales. Comunicación de Ecuador" adoptado el 27 de febrero de 2013. (IP/C/W/585IP/C/W/585)

OMS/UNICEF. 2012. Progresos sobre el agua potable y saneamiento. Informe 2012 OMS -UNICEF, New York. 68 pp.ISBN: 978-92-806-4632-0

ONU. 2012. Conferencia de las Naciones Unidas sobre Desarrollo Sostenible Río+20 A/CONF.216/L.1: Río de Janeiro. 59 pp.

ONU. 2015. Convención Marco sobre el Cambio Climático. Anexo Acuerdo de París (U.N. Doc. FCCC/CP/2015/L.9, 12 de diciembre de 2015)

ONU. 2015. Objetivos del Desarrollo del Milenio. Informe de 2015. Ediciones Naciones Unidas, Nueva York. 72pp.

ONU. 2015. Proyecto de documento final de la cumbre de las Naciones Unidas para la aprobación de la agenda para el desarrollo después de 2015. Anexo Transformar nuestro mundo: la Agenda 2030 para el Desarrollo Sostenible (U.N. Doc. A/69/L.85, 12 de agosto de 2015)

ONU. 2016. Leonardo DiCaprio llama a la audacia para mitigar el cambio climático. La ONU y el Cambio Climático. (Fecha de acceso 1de noviembre de 2016) URL disponible en: http://www.un.org/climatechange/es/blog/2016/04/ leonardo-dicaprio-llama-la-audacia-para-mitigar-elcambio-climatico/

ORR, D. 2004.The Nature of Design: Ecology, Culture, and Human Intention. Oxford University Press Inc., Nueva York.248pp.

PACKARD, V. 1968. Los Artífices del Derroche Editorial Sudamericana, Buenos Aires. 373pp. 
Ambiente y Sostenibilidad 2016 (6): 105-135

Revista del Doctorado Interinstitucional en Ciencias Ambientales

PÉREZ, D. 2014. China monopoliza todas las tierras raras, esenciales para la tecnología. El Confidencial. Sección Tecnología. 28 de enero de 2014. (Fecha de acceso el 7 de junio de 2016. URL disponible en: http://www.elconfidencial.com/tecnologia/2014-0128/china-monopoliza-todas-las-tierras-raras-esencialespara-la-tecnologia_81222/

PORCELLI, A. 2014. Vinculaciones entre el Derecho Informático, las Nuevas Tecnologías de la Información y Comunicación y el Ambiente: Impacto de la Tecnología Informática en el Ambiente. Tecnologías verdes. Revista Electrónica del Departamento de Ciencias Sociales de la UNLU, RED Sociales (2): 105-136

PORCELLI, A. \& MARTíNEZ, A. 2016.La Nueva Economía del Siglo XXI: análisis de los impactos de la Informática en el Ambiente. Tendencias Actuales en Tecnologías Informáticas Verdes, un compromiso con la Sustentabilidad" Revista Quaestio Iuris 4, (8) Número Especial (2015): 2174-2208

PROGRAMA DE NACIONES UNIDAS PARA EL MEDIO AMBIENTE. UNEP. 2015. Estrategia Regional de Consumo y Producción Sostenibles (CPS) para la implementación del Marco Decenal de CPS (10YFP) en América Latina y el Caribe (2015-2022) UNEP.

RECYCLA, CHILE. 2007. Residuos electrónicos (EWASTE), la nueva basura del siglo XXI. Una AmenazaUna Oportunidad.Fundación Casa de la Paz, Santiago de Chile. 74pp.

RTVE. Radio y Televisión española digital. 2011. Comprar, tirar, comprar. (Fecha de acceso 12 de agosto de 2016) URL disponible en: http//www.rtve.es/television/documentales/comprar -tirar-comprar/

SECRETARÍA DE MEDIO AMBIENTE Y RECURSOS NATURALES DE LA REPÚBLICA DE MÉXICO. 2014. Consumo Sustentable: Un Enfoque Integral. México: Semarnat, México. 25pp. ISBN: 978-607-8246-20-5

SENNETT, R. 2006. La cultura del nuevo capitalismo. Anagrama, Barcelona.185pp.

SILVA, U. 2010. Los residuos electrónicos (RE) en la Sociedad de la Información en Latinoamérica. En: UNESCO (ed.) Plataforma Regional de Residuos electrónicos para América Latina RELAC. Los residuos electrónicos: Un desafío para la Sociedad del Conocimiento en América Latina y el Caribe: 19-
ISSN: 2339-3122

41.UNESCO RELAC, Montevideo, p.30

SPETH, J. 2008. The Bridge at the Edge of the World: Capitalism, the Environment, and Crossing From Crisis to Sustainability. Yale University Press, New Haven. 320pp.

STIGLITZ, G. 1983. Tutela del ambiente y del consumidor. Dos recientes soluciones en Derecho español. LA LEY 1983-D, 793.

TAMBUSSI, C. 2015 Sobre la necesidad de actuar ante el fenómeno de la obsolescencia programada. ElDial DC202C 6 de noviembre de 2015 Editorial Albrematica S.A, Argentina.

TECNOLOGÍA PARA CUIDAR EL MEDIO AMBIENTE. (editorial) Revista Claves 21 Ambiente y Desarrollo Sustentable. (Fecha de acceso 15 de julio de 2016) URL disponible en: http://claves21.com.ar/tecnologia-verde-herramientaspara-cuidar-el-medio-ambiente/

UNIÓN EUROPEA.UE. 2003. Directiva 2002/96/CE del Parlamento Europeo y del Consejo, del 27 de enero de 2003, sobre residuos de aparatos electrónicos o eléctricos. (Diario Oficial de la Unión Europea, L.37, del 13 de febrero de 2003, artículo 3 pp. 24 - 39).

UNIÓN EUROPEA. UE. 2005. Directiva 2005/29/CE del Parlamento Europeo y del Consejo, de 11 de mayo de 2005 , relativa a las prácticas comerciales desleales de las empresas en sus relaciones con los consumidores en el mercado interior (Diario Oficial de la Unión Europea, L.149, del 11 de mayo de 2005, pp. 22-39)

UNIÓN EUROPEA. UE. 2012.Directiva 2012/19/UE del Parlamento Europeo y del Consejo, del 4 de julio de 2012, sobre residuos de aparatos electrónicos o eléctricos(RAEE) (refundición) (Diario Oficial de la Unión Europea, L.197, del 24 de julio de 2012, artículo 4 pp. 38 - 70)

VILCHIS-ONOFRE, A. et al. 2016. Dinámicas Capitalistas para la Acumulación del Despojo. Rev. Ciencias Sociales Universidad de Costa Rica 151: 31-41

WORLD ECONOMIC FORUM. WEF. 2009. Sustainability for tomorrow's consumer. The business case for sustainability. WEF, Ginebra.40pp. 